\title{
The role of venture quality and investor reputation in the switching phenomenon to different types of venture capitalists
}

\author{
Annalisa Croce $^{1} \cdot$ Elisa Ughetto ${ }^{2,3}$ \\ Received: 5 December 2018 / Revised: 4 February 2019 / Accepted: 5 February 2019 / \\ Published online: 18 February 2019 \\ (c) Associazione Amici di Economia e Politica Industriale 2019
}

\begin{abstract}
We examine how the perceived quality of a venture and the reputation of the incumbent Venture Capitalist (VC) are affecting the propensity to switch from an independent VC (IVC) to another IVC, to a governmental (GVC), a bank-affiliated (BVC) and a corporate (CVC). We find that high perceived quality ventures are more likely to switch from a IVC to another IVC, for whatever level of reputation of the incumbent. The quality of the venture matters in the switching to a BVC too, when the reputation of the incumbent IVC is not particularly high. Conversely, the lower is the perceived quality of the venture and the lower is the reputation of the incumbent IVC, the higher is the likelihood to rematch with a GVC. Finally, results also suggest that the probability of successful exit increases when a switching occurs from an IVC to a new lead IVC or to a CVC.
\end{abstract}

Keywords Switching $\cdot$ VC types $\cdot$ Venture quality $\cdot$ VC reputation

JEL Classification G24 · L26 · L2

\section{Introduction}

Venture capital investors (VCs) devote considerable effort to deciding in which entrepreneurial ventures to invest in order to filter out poor investment opportunities. In principle, a positive sorting mechanism characterizes the $\mathrm{VC}$ market: on the one hand, more reputable and experienced VCs tend to "cherry-pick" the best companies

\footnotetext{
Elisa Ughetto

elisa.ughetto@polito.it

1 Politecnico di Milano, DIG, Milan, Italy

2 Politecnico di Torino, Turin, Italy

3 Bureau of Research on Innovation, Complexity and Knowledge (BRICK), Collegio Carlo Alberto, Turin, Italy
} 
(Bertoni et al. 2016), on the other hand, higher quality entrepreneurial ventures actively seek VC and favour likewise more reputable VCs (Hsu 2004; Sørensen 2007).

Entrepreneurial ventures can be funded by one VC or by a group of VCs acting in syndication, where a lead investor is responsible for the deal (i.e. sets the price and terms of the investment, provides a large part of the capital, and usually agrees to represent the entire round on the board). Before each follow-on round takes place, investments are carefully re-evaluated. A large amount of investments is quickly exited because the extant VC prefers to focus its own resources on prospective "home runs". Ventures that are able to raise money in follow-on rounds can continue to be funded by the same VC or by a new one. Whenever the lead VC in previous financing rounds changes in the current round, a switching of lead VC takes place.

While the mechanisms affecting the initial selection of the ventures by VCs have been largely investigated (Fitza et al. 2009; Fried and Hisrich 1994; Shepherd 1999), the subsequent dynamics concerning the decision of both VCs and entrepreneurial ventures to maintain the extant relationship in follow-on rounds rather than to exert the abandonment option have received relatively little attention. This is quite surprising given the relevance of the phenomenon. In fact, it has been observed that from 1991 to 2002 in the $23 \%$ of the cases lead VCs of follow-on rounds of financing are different from those of previous rounds (Cumming and Dai 2013).

To our knowledge there are only two works explicitly studying the switching phenomenon in the VC industry (Abrardi et al. 2018; Cumming and Dai 2013). Another related small group of studies look at the dynamics that stimulate the investment by other VCs in follow-on rounds, also when mixed funding applies (Brander et al. 2015; Guerini and Quas 2016). Cumming and Dai (2013) analyse the switching phenomenon using a sample of 1385 US VC investment rounds. The authors, who consider only investments by independent venture capital funds (IVCs), find that ventures whose perceived quality is upwardly revised are more likely to switch to more reputable IVCs and to accept lower pre-money valuation and smaller investment size in follow-on rounds. Abrardi et al. (2018) propose a formal theoretical model to explain why an incumbent VC should "dump" a venture and a new VC should take it on. They concentrate on the circumstances in which the switching occurs from a lead IVC to a governmental VC (GVC) and vice versa. The model is empirically tested on a sample of 15,218 rounds of financing in 10,912 entrepreneurial ventures in the US between 1998 and 2010. Their analysis sheds light on the puzzling evidence that new and more reputable lead GVCs are more likely to invest in low economic return ventures (previously backed by an IVC), but at the same time they are more inclined to drop them in favour of a less-reputable IVC.

We build on the empirical findings of Abrardi et al. (2018) by examining the switching phenomenon in the light of different VC investor types. VCs represent a heterogeneous crowd with different governance structures. They can be independent

\footnotetext{
1 However, this might not always happen in thin VC markets where the matching process between ventures and VC investors is often driven by the selection of companies in need, rather than best performing companies (see the "frog kissing" versus "cherry picking" arguments developed in the theoretical model by Bertoni et al. 2016).
} 
firms where a management company (general partner) is investing capital raised from limited partners (IVCs). In this type of governance structure, general partners are independent in their investment selection and management and are not subject to any interference by limited partners. The governance of captive (i.e. non-independent) firms implies that a parent company (i.e. a financial institution in case of BVCs, a corporation in case of CVCs or a governmental body in case of GVCs) can exert a substantial influence on the management of the fund. A growing body of research has started to recognize the heterogeneity of VC firms (Bertoni et al. 2015; Manigart et al. 2002; Norton and Tenenbaum 1993), focusing on how they differ in terms of evaluation methods, competences, investment patterns, governance mechanisms and objectives. However, these different governance schemes, which affect investors' investment strategy and portfolio management (Bertoni et al. 2015; Manigart et al. 2002) are likely to influence switching behaviours as well. So far, there has not been any scholarly attempt in the literature to relate structural differences in the VC funds' governance to switching dynamics.

Discussing why switching occurs and the way it affects different types of VCs, driven by different governance mechanisms, is central to study the interplay between strategy and financing in entrepreneurship. Moreover, exploring the complementarity between the perspectives of incumbent and new VCs and that of entrepreneurs provides insights that have not been combined so far in the context of previous literature on VC switching.

In this study, we are not able to identify which is the subject who actually takes the initial decision to switch. In that regard, we have made an effort to provide strategic considerations of why some entrepreneurial ventures may switch from one investor to another one, looking at two relevant dimensions: the perceived quality of the venture and the reputation of the incumbent $\mathrm{VC}$. We thus assume that the roles played by the incumbent VC's reputation and by the ventures' perceived quality may explain the patterns of the two sided-matching between entrepreneurs and VCs and its potential dynamic adjustment. However, so far, little is known on the effects that venture quality and VC reputation entail on the change of lead investor and how these effects vary when different types of VC governance structures are considered.

Differently from Abrardi et al. (2018), we investigate whether and how the perceived quality of a venture and the reputation of the incumbent $\mathrm{VC}$ are affecting the propensity to switch from an IVC to another IVC, or to other types of VC investors (e.g. GVC, BVC and CVC). The discussion on the switching between an IVC and a GVC is reintroduced for allowing a comparison of the switching dynamics across all the different types of investors. In addition, we also intend to provide some evidence on the effect of switching the type of lead VC investor on both the performance of entrepreneurial ventures [proxied by the probability of successful exit via an initial public offering (IPO)] and the evaluation that they receive at the time of financing.

The remainder of this paper is organized as follows. The second section puts forward some testable hypotheses in the context of prior research. The third section introduces the dataset and the summary statistics. The fourth section presents the econometric models used and illustrates the results. The final section concludes the paper and discusses the implications of our findings. 


\section{Theoretical background}

In this section we gain insight into the economic motivation for switching by looking: (1) at the reasons underlying the switching phenomenon, that relate both to the supply side (VC) and demand side (venture) of financing, (2) at the roles played by the incumbent $\mathrm{VC}$ reputation and by the venture perceived quality by examining the behaviour of different institutional types of VCs: IVCs, GVCs, BVCs and CVCs. (3) at the impact of the different typologies of switching on ventures' probability of successful exit.

\subsection{Switching lead VC investor}

We acknowledge that studying VC switching is challenging because the dynamics at work are complex and multifaceted. There are positive and negative factors affecting the switching decision related to both the supply and demand sides of financing. The observed phenomenon may be the result of $\mathrm{VC}$ dumping (the decision to not participate as lead investor in subsequent offerings), entrepreneur switching, or in some cases, both (either simultaneously or sequentially). Switching lead investor also implies that a new VC chooses to or gets invited to participate as lead investor in the new round. While it can be assumed that one specific actor initiates switching, the decision to change lead investor is presumably taken collegially.

The aim of this study is to explore this switching process by invoking different theoretical perspectives. One main reason why an incumbent VC may decide not to participate as lead investor in subsequent rounds is that it is not fully satisfied with the realized performance of the venture. In that case, the switching occurs for pure financial return reasons. Alternatively, or additionally, divergent views or objectives between the venture and the VC might entail agency problems, leading a current VC to abandon the venture in subsequent rounds. In fact, early stage ventures are characterized by a much wider dispersion than established firms of possible (and realized) outcomes, which is a function of enhanced information asymmetry (Cumming and MacIntosh 2001). Agency problems arise if entrepreneurs, endowed with superior information compared to outside investors on their ventures' technology and business potential, decide to deviate from the investors' strategic objectives. Although many contractual arrangements are shaped by the need to provide active monitoring and to better align entrepreneurs' incentives to those of investors (Gompers 1995), the opportunistic behaviour that investee ventures can engender might not be completely under control.

The switching process can be initiated by entrepreneurial ventures too. At the new round, the board contemplates the full range of available investors. The assessment of the potential funding alternatives can be made ex-ante (before the decision to switch) or ex-post (conditioned on the decision to switch). One option for entrepreneurial ventures is to evaluate whether or not to switch from the specific existing investors. Another option is instead to contemplate the various alternative investors conditioned on the decision to switch. An additional decisional layer concerns the possibility to switch to a new VC of the same type (e.g. from an IVC to a new IVC) 
or of a different type (e.g. from an IVC to a new GVC, CVC or BVC). ${ }^{2}$ All these decisions imply different strategic considerations and reflect context and organizational specific settings in which entrepreneurial firms compete.

One of the main potential reasons why an entrepreneurial venture should switch $\mathrm{VC}$ is that it perceives that the current $\mathrm{VC}$ is not sufficiently active or skilled for achieving an exit by IPO or acquisition. Provided that the benefits of switching are greater than the costs, switching to a new VC might be attractive especially if it is more reputable or resource endowed than the incumbent one: ventures could potentially raise higher amounts of capital in follow-on rounds, access further deal opportunities and presumably receive more valuable advice and coach to increase their chances of a successful exit and higher valuations at exit.

The decision of a VC to become the new lead investor in a deal might be driven by reputational concerns too, especially when the incumbent VC is a highly reputable investor. Reputation is a valuable intangible resource that creates positive external perceptions about the VC's trustworthiness and legitimacy ( $\mathrm{Gu}$ and $\mathrm{Lu} 2014$; Turban and Cable 2003) because it leads to the public recognition of the otherwise unobservable quality of the VC (Lee et al. 2011). In this case, the endorsement of the affiliation with a prominent and highly reputable VC could represent a signal (even if less durable than other signals of quality, like patents or founding team characteristics - see Kolympiris et al. 2018) to third parties of the quality of the new VC (Lee et al. 2011). However, as noted by Cumming and Dai (2013), agency problems might arise between the two VCs if the new VC is invited by the incumbent VC to become the new lead investor for a deal whose quality has been revised downward or if it has to pay too much for it.

\subsection{Switching from an IVC to another type of VC}

The dynamics that affect both the ex-ante selection process of target companies and their post-acquisition management and abandonment options are influenced by the institutional characteristics of VC funds and are illustrated in Fig. 1. We explore these aspects from the perspectives of both entrepreneurs and VCs.

\subsubsection{Switching from an IVC to another IVC}

The managers of an IVC typically invest in those ventures that exhibit expected returns higher than a minimal threshold (or risk-variance frontier). Since IVCs pool and manage money from investors who are interested in ensuring a return on investment, they need to exhibit above-average returns if they want to raise subsequent funding from third parties (Lee et al. 2011; Manigart et al. 2002). The objective function of IVCs is therefore to maximize their net capital gains in order to establish new rounds of financing and achieve a higher deal flow (Lee and Wahal 2004). As

\footnotetext{
${ }^{2}$ In our analysis, we cannot distinguish whether the board of invested ventures evaluates ex-ante (before the decision to switch) or ex-post (after the decision to switch) the opportunities that are available on the market (in terms of the full range of investors). We can just model the fundamental option of switching or not lead investor and, in case the switching takes place, the type of switching.
} 


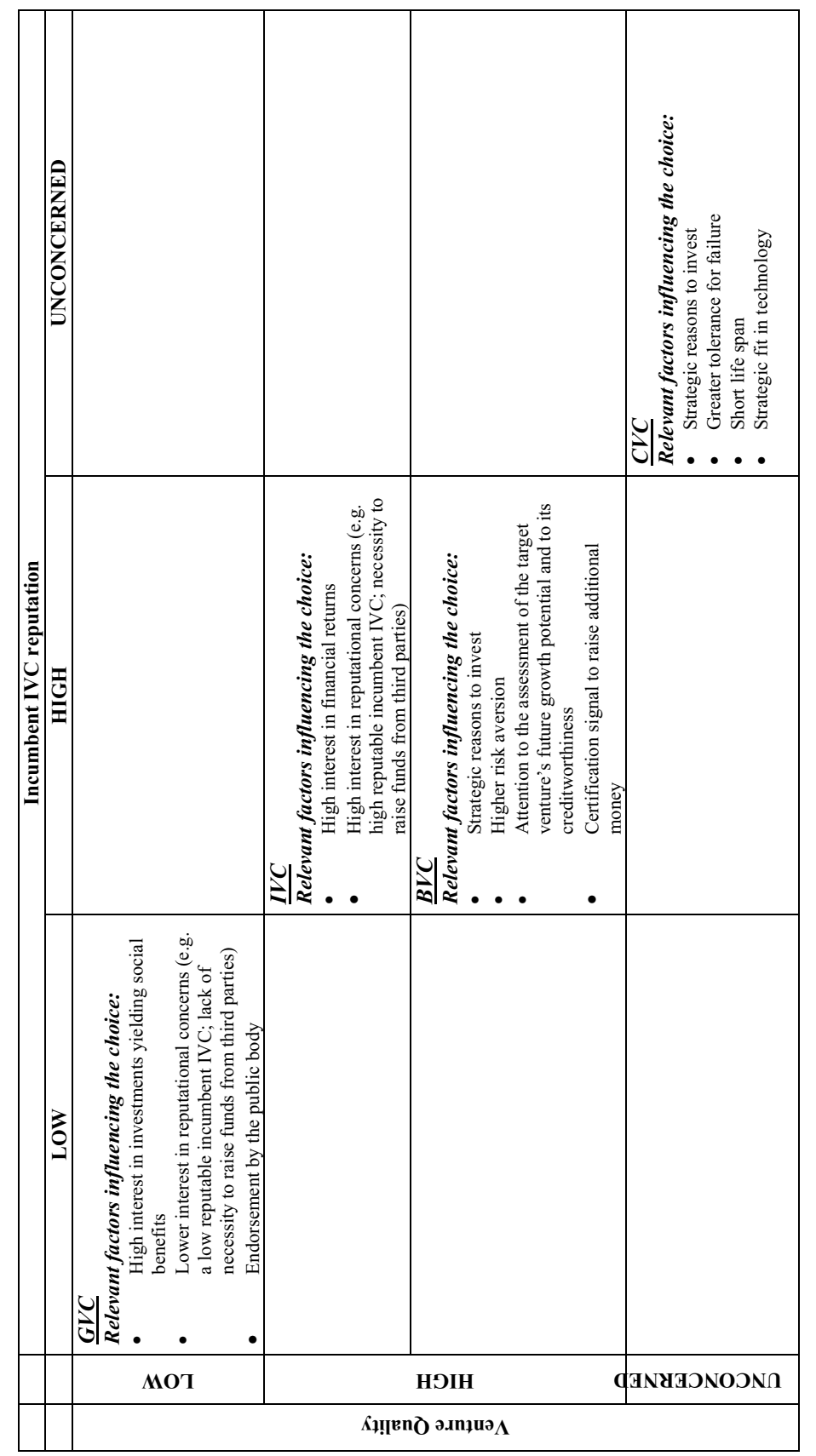

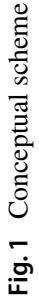


shown by Cumming and Dai (2013), when the switching involves two IVCs, the new IVC will take on a venture only if it shows good prospects of going public (Gompers and Lerner 2000) or of getting acquired at a high price. Thus, when a switching takes place, the new IVC will be primarily interested in taking on a venture with a high perceived quality.

Moreover, the switching decision might also be positively influenced by the reputation of the lead incumbent IVC. Since the quality of an early stage venture is often difficult to evaluate, being backed by a reputable IVC can represent a signal to the financial market that the venture is valuable, thus potentially inducing other subjects (managers, investors, suppliers) to commit time and resources to it (Fitza et al. 2009; Gompers 1995; Hsu 2004; Nahata 2008). We thus expect that the higher is the perceived quality of the entrepreneurial ventures and the higher is the reputation of the incumbent IVC, the higher is the probability that they switch from an IVC to a new lead IVC.

\subsubsection{Switching from an IVC to a GVC}

The selection process of GVCs is typically biased toward investments that generate higher spillovers or localised public benefits (Grilli and Murtinu 2014). The public investor is interested in sustaining investments that yield high social benefits to society as a whole, in some cases, to the detriment of financial returns. GVCs usually target specific geographical areas where their intervention is motivated and legitimized by a perceived "market failure" or "financing gap" (Bertoni et al. 2015; Lerner 2002). A direct consequence of this investment strategy is that ventures which are potentially beneficial to the social welfare, but showing relatively lower expected returns, could be selected by GVCs and kept in a portfolio for a longer period than private investors would choose (Buzzacchi et al. 2013). GVCs do not have rigorous financial return requirements, are less subject to reputation constraints because they do not have to raise funding from third parties and have no clearly defined exit strategy. It is generally argued that the screening undertaken by GVCs, although not necessarily inferior to that of IVCs (Lerner 2002, page 78), may be subject to severe distortions if GVCs are subject to political interests and pressure groups (Afful-Dadzie and Afful-Dadzie 2016; Becker 1983). Overall, scholars have been sceptical of whether GVCs have adequate skills and managerial incentives to select the most promising ventures (Grilli and Murtinu 2014, 2015; Jääskeläinen et al. 2007; Leleux and Surlemont 2003).

If GVCs have a greater tolerance for lower returns (providing that other goals are being met), they might attract ventures whose quality was downwardly revised by incumbent VCs. This effect should be, ceteris paribus, more pronounced if the venture is associated with a poorly reputable IVC.

From the venture's perspective, a low quality venture lacking the "certification effect" that being backed by a reputable investor might engender in the VC market, will probably encounter greater difficulties in finding alternative sources of financing from other IVCs. Since its degree of quality is not necessarily a concern for GVCs (in case the venture is able to provide substantial positive externalities), switching to a GVC could be a viable alternative to a problem of resource constraints. In addition, entrepreneurial ventures with a low perceived quality might find it attractive to switch to a GVC because of the role that GVCs play in directing private capital 
towards investment opportunities that otherwise would have not been considered (Devenow and Welch 1996). A venture could indirectly benefit from these certification effects through a facilitation in the access to additional finance in form of financial debt, operational debt, or external equity. The endorsement by a GVC could act as a "stamp of approval" (Lerner 2002, page 78), thus facilitating companies' access to outside investors (Guerini and Quas 2016). Being backed by a GVC might also provide the venture of governmental contacts that could help it to access streamlined and faster regulatory approvals of business matters (Cumming et al. 2017).

We thus assume that, in the case of GVCs, differently from IVCs, there is a positive interplay between venture quality and existing VC reputation in the switching decision: a low perceived quality venture shows a higher probability to switch to a $\mathrm{GVC}$, the lower is the reputation of the incumbent IVC.

\subsubsection{Switching from an IVC to a BVC}

The theory on VC has highlighted that BVCs make investments in entrepreneurial ventures not merely to obtain financial returns, but also for strategic reasons (Andrieu 2013; Hellmann 2002; Hellmann et al. 2008). In fact, banks that extend their expertise into venture investing pave the way for the building of future bank-customer relationships. By forging a relationship with a firm at the VC stage, banks hope to create future customers for their lending and underwriting activities (Croce et al. 2015). BVCs are more inclined to invest locally, where they can best gather soft information on future customers (Bertoni et al. 2015). BVCs are also typically more risk-adverse than IVCs, because they have less pressure to maximize returns, since they do not need to worry about raising follow-on funds from third parties (Manigart et al. 2002). Even though BVCs do not have the exclusive goal of profit maximization as IVCs, but also strategic reasons, there is a clear concern by BVC fund managers that funds are used efficiently and properly allocated by portfolio firms. Hence, BVC fund managers have incentives to properly screen and select the best possible targets.

When a switching occurs, we therefore expect that the new lead BVC will pay attention, as a bank would do, to both the assessment of the target venture's future growth potential and to the reputation of the incumbent IVC. The indirect effect of a reputable IVC is the guarantee that all possible efforts to increase the venture's prospects and creditworthiness have been made (Gompers and Lerner 1998; Lee and Wahal 2004; Sahlman 1990; Sørensen 2007).

From the venture's perspective, a high quality venture might be interested in switching to a BVC to reap the benefits of an increase in the availability and quantity (and possibly decreased cost) of credit, either from the bank itself or from other banks. All else being equal, the relationship developed between a bank and a venture at the VC level should convey a signal that certifies the quality of the venture to other banks (Lee and Wahal 2004) and facilitates its access to additional finance in the form of financial debt, operational debt, or external equity. This may increase capital infusion into the venture, by leveraging on additional complementary financial resources. Moreover, BVCs are under less pressure to divest early and can easily provide additional capital in subsequent financing rounds (Andrieu and Groh 2012). 
We thus theorize that there is a positive interplay between a venture's perceived quality and the switching to a new lead BVC, and that this relationship is strengthened the higher is the reputation of the incumbent IVC.

\subsubsection{Switching from an IVC to a CVC}

The investment strategy of CVCs is mainly driven by strategic reasons. Besides the objective of achieving a substantial financial return on investment, one of the leading motivations for a CVC to undertake an investment is to gain a window on valuable and novel technologies, so as to advance the company's innovative efforts. In fact, through a CVC investment, an established company can build linkages/alliances to entrepreneurial ventures to gain access to new knowledge that can revitalize its innovation activities (Dushnitsky and Lenox 2005) and be used to build new capabilities or to strengthen existing ones. Firms endowed with strong technological and marketing resources are typically engaged in greater CVC activity.

Research also shows that the investment portfolios of CVC investors exhibit a significant degree of diversity (Lin and Lee 2011; Wadhwa et al. 2016), which is linked to different investment practices, some of which are the result of pressures to conform to the parent mandates. Souitaris and Zerbinati (2014), using a multiple case study, distinguish between "integrated" and "“arm's length" investment logics. The first investment practice is aligned with the norms of the parent company and aims at securing the strategic and organizational fit with the corporation. The latter is instead more aligned with the dictates set by the VC industry and less emphasis is placed on corporate investment practices.

It has been highlighted that the uncertainty associated with potential financial and strategic benefits, the short life span of CVC programs and the failure to attract and retain seasoned fund managers (Gompers and Lerner 1998, 2001) makes CVCs less effective in properly selecting portfolio ventures. This often leads to an overpricing of investments compared to those of IVCs (Gompers and Lerner 1998). Moreover, CVCs are also found to be patient investors and to have a greater tolerance for failure (Chemmanur et al. 2014; Colombo and Murtinu 2017).

We can therefore assume that, when a switching occurs, a CVC will evaluate the venture more as an effective route to innovation for achieving strategic synergies with the corporation's core business and for exploiting corporate resources and capabilities. Thus, the CVC will pay less attention to the venture's perceived quality and to the reputation of the incumbent IVC, because the main goal is to channel the venture's activities and technology to the investor's organization.

From the venture's side, the endorsement by a CVC provides benefits to the venture in terms of access to the capabilities, resources (e.g. technologies, distribution channels, human capital, production capacity, brand) and network of industry contacts (e.g. customers, suppliers) of the parent organization. However, it is not obvious that an entrepreneurial venture will want its investors to be pursuing strategic objectives (Hellmann 2002). Hellmann (2002) theorizes that only if the venture is a complement to the strategic partner it is optimal for it to obtain funding from a CVC. The strategic fit between the technology of the venture and that of the parent 
organization of the CVC fund is therefore driving the choice for a CVC, especially in markets where R\&D competition is high (Fulghieri and Sevilir 2009).

In addition to funding, a venture might benefit from a CVC if this latter is able to provide value added services or to facilitate the venture's access to complementary assets, endorsements, and international product markets (Dushnitsky and Lenox 2005; Wadhwa et al. 2016). However, appropriability concerns may induce ventures to hesitate to share sensitive information with a corporate VC (Dushnitsky and Lenox 2005) and potential conflicts of interest are likely to arise, which could ultimately have detrimental effects on portfolio firms' performances. We thus expect that, both the perceived quality of the entrepreneurial ventures and the reputation of the incumbent IVC, are not influencing the probability of switching from an incumbent IVC to a new lead CVC.

\subsection{Switching lead investor and ventures' probability of successful exit}

Institutional differences among VCs can affect their investment strategy and the performance of portfolio ventures. Investors with diverse backgrounds and objectives can exercise different skills and expertise that conducts to different performance outcomes. In general, prior literature is consistent with the view that captive VCs tend to be less involved in providing value-added activities to portfolio companies than IVC funds, and that this in turn is likely to affect firm ultimate performances.

As it was previously discussed, experiencing successful portfolio exits is the main goal for IVCs, since they pool and manage money from external investors (Gompers and Lerner 2001). Seeking high financial returns by funding growth-oriented ventures from which later exiting via an IPO is instead less relevant for both CVCs and BVCs, which are pursuing strategic objectives, and for GVCs, that emphasize the strategic and socially oriented implications of their investments. This does not mean that GVCs, CVCs and BVCs do not have the goal to foster the growth of their portfolio firms, but that there are other issues at stake beside the search for financial returns.

The different types of investors are also differently effective in driving investee ventures to a successful exit (Tykvova and Walz 2007). IVCs typically have an active and on-going involvement in the management and monitoring of their businesses and offer value-added services to portfolio ventures in fields such as strategic planning, finance, accounting, marketing and human resources management, by providing connections and experience to entrepreneurs (Baum and Silverman 2004; Hellmann and Puri 2002). The success of investing is ultimately contingent upon the coaching that IVCs can provide to their investees. Moreover, compensation structures that are strongly incentivising IVC managers to pursue the maximization of financial returns are also important determinants affecting the success of an investment.

CVCs also assist portfolio companies by providing value-added services similar to IVC funds, by leveraging corporate resources and endorsing the venture's third parties (Dushnitsky and Lenox 2005). A considerable number of studies have compared the impact of IVC and CVC investors on portfolio firms' growth (Bertoni 
et al. 2015; Colombo and Murtinu 2017), successful exit (Park and Steensma 2012) and innovation (Chemmanur et al. 2014; Park and Steensma 2013). Overall, CVCbacked companies are found to perform better than their peers when they have a strategic fit with the corporation, are in search for complementary assets and their investments have a long-term horizon.

Instead, BVCs are not typically "hands-on" investors, and as with all other captive investors, they lack independence in decision-making and this limits their effectiveness in bringing ventures to a successful exit. The same reasoning applies to GVCs. GVCs generally have more limited resources than other investors, being particularly vulnerable to governmental budget cuts. Moreover, in many cases GVCs are not able to provide a reward structure for fund managers that matches the one of IVCs, thus finding it more difficult to recruit top level staff with investing experience (Cumming et al. 2017; Grilli and Murtinu 2014). Even if they introduce rewards for positive performances in line with IVC practices, the expected returns in market failure areas are not enough high to attract highly competent professional managers to participate in these funds (Jääskeläinen et al. 2007; Leleux and Surlemont 2003). GVCs monitor portfolio firms less closely than IVCs, using fewer and less efficient contract mechanisms, which represent powerful incentives for entrepreneurs to pursue growth and efficient tools for fund managers to mitigate agency problems (Kaplan and Strömberg 2004). GVCs might also be subject to the influence of political and pressure groups (Afful-Dadzie and Afful-Dadzie 2016, Becker 1983). Finally, the success of investing activity is also critically dependent upon an institutional environment of technical, social, financial networks and business support services, which are notably deficient or limited in lagging areas characterized by the intervention of GVCs. We thus expect that the switching from an IVC to another IVC or to a CVC have a positive effect on the probability of successful exit of entrepreneurial ventures.

\section{Data sources and sample characteristics}

Data on venture investments are extracted from Thomson One database (formerly known as Venture Xpert). We extracted all VC investments made in the United States from 1998 to $2010 .{ }^{3}$ We also collected data from the US Bureau of Economic Analysis (BEA) on the GDP per capita and matched this information with the state in which sample entrepreneurial ventures are located in the year of the investment round. To control for the state of the stock markets at the time the switching occurs, we collected data on the Morgan Stanley Capital International (MSCI) annual index returns for the US stock market.

\footnotetext{
3 The extraction refers to April 2012. We decided to compare the switching dynamics affecting the only VC industry, by considering the heterogeneity within the industry and thus the different types of VCs, without introducing other forms of financing (e.g. business angels, buyouts and non-equity based funding). The VC industry presents specific characteristics and patterns that are not directly comparable with other forms of financing. Adding other forms of equity or non-equity financing would make such comparison less interesting. Moreover, the Venture Expert's data coverage on business angels and non-equity deals is today still insufficient.
} 
Table 1 Distribution of the number of rounds and ventures for the different typologies of switching

\begin{tabular}{|c|c|c|c|c|}
\hline & First round & Follow-on rounds & Total & Number of switchings \\
\hline Number of rounds & $7548(44.8 \%)$ & $9298(55.19 \%)$ & 16,846 & $4462(26.48 \%)$ \\
\hline \multirow[t]{2}{*}{ Number of ventures } & $7548(61.9 \%)$ & $4645(38.09 \%)$ & 12,193 & $2927(24 \%)$ \\
\hline & $\begin{array}{l}\text { Switching from } \\
\text { an IVC to an IVC }\end{array}$ & $\begin{array}{l}\text { Switching from an } \\
\text { IVC to a GVC }\end{array}$ & $\begin{array}{l}\text { Switching from } \\
\text { an IVC to a BVC }\end{array}$ & $\begin{array}{l}\text { Switching from an } \\
\text { IVC to a CVC }\end{array}$ \\
\hline $\begin{array}{l}\text { Number of switch- } \\
\text { ing rounds }\end{array}$ & $3854(86.37 \%)$ & $235(5.26 \%)$ & $188(4.21 \%)$ & $185(4.14 \%)$ \\
\hline $\begin{array}{l}\text { Number of switch- } \\
\text { ing ventures }\end{array}$ & $2553(87.22 \%)$ & $227(7.75 \%)$ & $183(6.25 \%)$ & $178(6.08 \%)$ \\
\hline
\end{tabular}

According to Abrardi et al. (2018), a lead VC is defined as the one that, in the specific round, has invested the largest amount of capital. ${ }^{4}$ Ventures whose lead investor was unknown and that did not have complete records on the amount invested in each round and on the commitment of the lead VC investor were dropped. In order to extend the results by Cumming and Dai (2013) that focus on the switching among IVCs, we included in our sample the switching rounds from an IVC to other typologies of VC investors, namely GVCs, BVCs and CVCs.

The final sample consists of a total of 16,846 rounds of financing in 12,193 entrepreneurial ventures between 1998 and 2010. Of the 16,846 rounds of financing, 9298 rounds are follow-on rounds. Out of 12,193 ventures, 7548 received only one round of financing, while 4645 received more than one round of financing during the sample period. Among these latter firms, 2927 ventures experienced a switching of the lead investor in at least one of the subsequent rounds. We observe a total of 4462 rounds of switching (47.99\% of the follow-on rounds of financing). In particular, 3854 rounds refer to the switching from an IVC to another IVC, 235 rounds concern the switching from an IVC to a GVC, 188 rounds are relative to the switching from an IVC to a BVC and 185 rounds refer to the switching from an IVC to a CVC. ${ }^{5}$ Table 1 reports the distribution of the number of rounds and ventures for the different typologies of switching.

Table 2 illustrates the distribution of the entrepreneurial ventures by industry, ${ }^{6}$ stage, location and exit between switchers (i.e. switchers from an IVC to another IVC, to a GVC, to a BVC and to a CVC) and non-switchers. Switching ventures are more likely than non-switchers to operate in the computer, internet, services, medical \& health, biotech and semiconductor sectors. In particular, among switching ventures, $53.26 \%$ are concentrated in the computer and internet fields, followed by services $(14.28 \%)$ and medical \& health $(13.26 \%)$. Ventures in later stages of

\footnotetext{
${ }^{4}$ Following Cumming and Dai (2013), as a robustness check, we also considered a lead VC as the one that invested the largest cumulative amount of capital. However, we did not find any significant difference in the results discussed in the next section.

5 Note that a venture may switch more than once in the observed period.

${ }^{6}$ We followed the industry classification provided by the Thomson One database.
} 


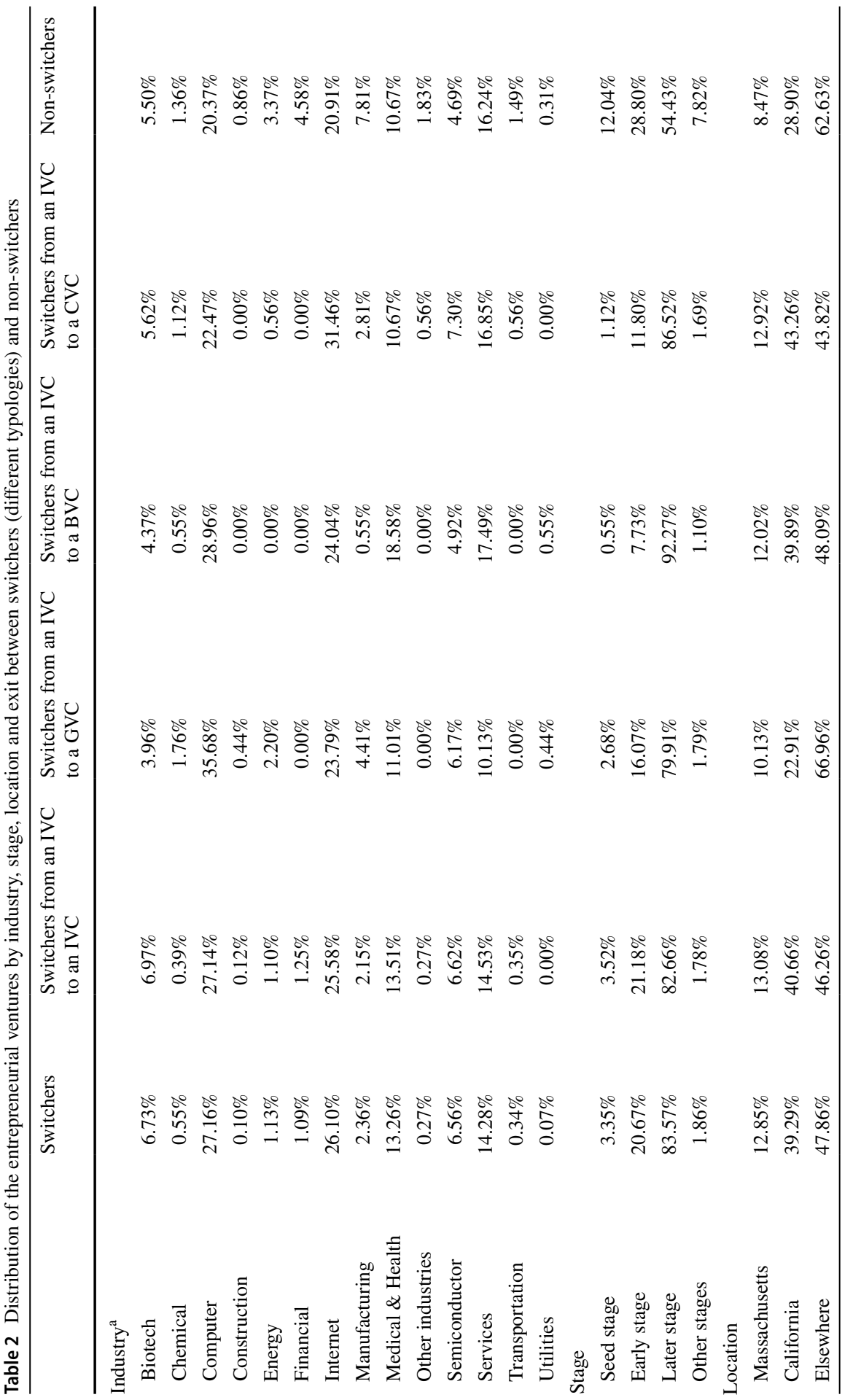




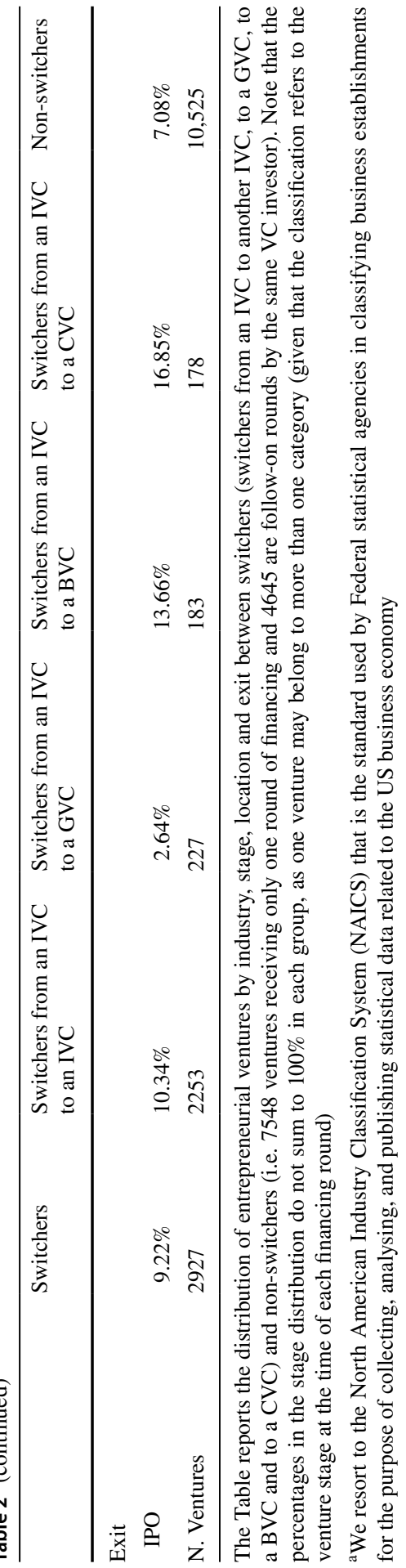


development are more likely to switch, as more than $80 \%$ of switchers are later-stage ventures. Ventures located in Massachusetts and California, where most VC investors operate and where $\mathrm{VC}$ networks are predominantly concentrated (Hochberg et al. 2007), are also more likely to switch. ${ }^{7}$ Finally, the results indicate that switchers are more likely to exit successfully compared to non-switchers.

Table 3 compares the reputation of the incumbent lead IVC (i.e. the lead IVC before the switching occurs) between non-switchers and switchers, through a $t$ test of differences in means. We followed the approach of Lee et al. (2011), ${ }^{8}$ by defining VC reputation through a multi-item index. In particular, we considered the following time variant measures (all based on the years prior to the focal year in which a VC invested in the specific venture as lead): the total number of portfolio companies the $\mathrm{VC}$ invested in; the total equity funds invested in portfolio ventures; the number of portfolio ventures taken public ${ }^{9}$; VC experience (calculated as the focal year minus the year in which the specific VC fund was created). We also controlled for the size of the VC fund by considering the total dollar amount of funds raised, the number of individual funds raised and the total number of deals of the individual fund. To create the reputation index, we conducted a factor analysis. The one factor model that we obtained enabled us to create a single measurement scale by aggregating all the described items. We compared our factor with the reputation index estimated by Lee et al. $(2011)^{10}$ : the correlation between our index and Lee et al. (2011)'s index is equal to 0.839 .

The statistics in Table 3 suggest that for those ventures switching from an IVC to another IVC, to a CVC and to a GVC, the incumbent lead VC has, on average, a lower reputation compared to the incumbent lead VC for non-switchers. From the ventures' perspective, this evidence might suggest that ventures change lead VC when they are not satisfied by the incumbent VC: the lower is the reputation of the incumbent lead VC, the higher is the probability that the venture is involved in a switching toward another VC investor. The difference with non-switchers is instead not significant for switchers from an IVC to a BVC.

Table 3 also compares the quality of the venture through a $t$ test of differences in means, by distinguishing between non-switchers and switchers. In order to measure the perceived quality of the entrepreneurial venture, we followed the approach suggested by Cumming and Dai (2013) and followed by Abrardi et al. (2018), who resort to the estimated probability of successful exit as a proxy of the entrepreneurial venture's perceived quality at the start of a new round. In particular, we ran a probit regression in which the dependent variable is equal to one if the venture exited as an IPO in year $\mathrm{t}$ or before, and zero otherwise. The independent variables are the

\footnotetext{
7 In Appendix A (Table 1A) we report the distribution of the number and percentage of switching rounds in the different US regions.

8 This approach has been followed also in Abrardi et al. (2018).

9 This number is estimated by year, by considering those IPOs for which the focal VC was the lead investor at the time of the last funding round.

${ }^{10}$ Lee et al. (2011)'s VC reputation index is available for public use at www.timothypollock.com. VC investors in our sample are not all included in Lee et al. (2011)'s index. The presence of these missing values explains why we replicate Lee et al. (2011)'s procedure instead of directly using their index.
} 


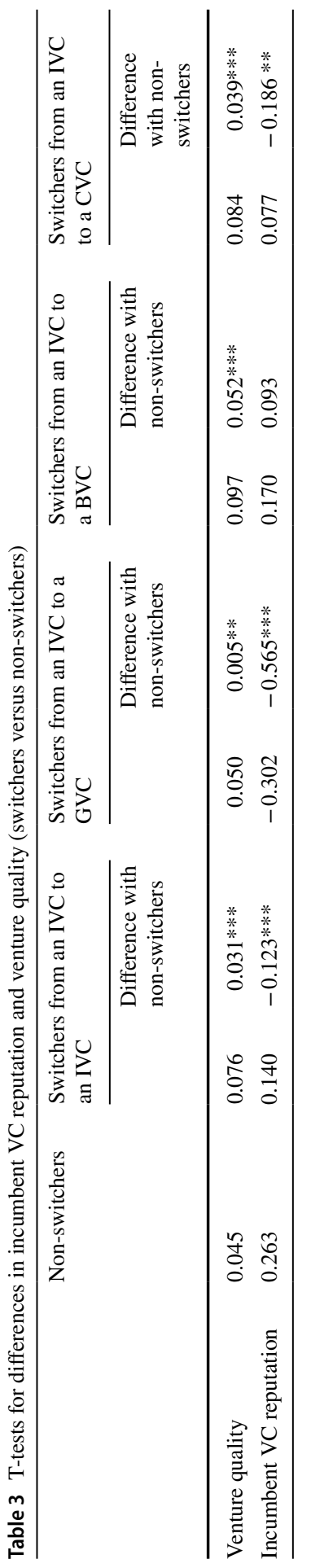


development stage of the entrepreneurial venture in year $\mathrm{t}$, the geographical location of the venture, the industry in which the venture operates, the size of the financing received by the venture until the year $t$, the number of rounds the venture received until the year $t$, and the size of the syndicate investing in the venture in year t. Our results confirm that all these variables are significantly correlated with the probability of IPO. ${ }^{11}$ We then estimated the predicted probability of a successful exit from the probit regression and used it as a proxy for the venture's perceived quality. We estimated the probability of a successful exit for each venture at the start of each round; therefore we employed a non-static measure of perceived quality.

The statistics in Table 3 suggest that the quality of switching ventures is higher than the one of non-switching ventures for all types of switching. However, it can be remarked that the difference in venture quality between non switchers and ventures switching from an IVC to a GVC is significant but of limited magnitude.

The definition and summary statistics of the variables used in the empirical analysis are provided in Tables 4 and 5 respectively.

\section{Results}

Following the empirical approach of Abrardi et al. (2018), we resort to a multinomial logit in order to estimate the effects of the reputation of the incumbent lead IVC and the perceived quality of the entrepreneurial venture ${ }^{12}$ on the different types of switching. More in details, we estimate the following multinomial logit model:

Switching type $=\mathrm{f}$ (perceived venture quality; incumbent VC reputation; perceived venture quality $*$ incumbent VC reputation; Controls).

Switching type is a categorical variable and assumes five different values: (a) switching from an IVC to another IVC, (b) switching from an IVC to a GVC, (c) switching from an IVC to a BVC, (d) switching from an IVC to a BVC and (e) nonswitching rounds taken as the baseline category. The likelihood to fall in the outcome $j$ is $p j=\frac{\exp \left(\dot{X} \beta_{j}\right)}{1+\sum_{j=1}^{5} \exp \left(\dot{X} \beta_{j}\right)} \cdot{ }^{13}$ We included several controls in our model specification. First, the size of the incumbent lead IVC (commitment in millions of \$) relative

\footnotetext{
11 Results of this regression are not reported in the text for the sake of brevity but are available from the authors upon request.

12 Please refer to the previous Section for details on the estimation of incumbent IVC reputation and perceived venture quality.

13 The concept of switching is unavoidably linked to follow-on rounds because we only observe switching behaviour for the restricted, nonrandom group of ventures which successfully obtained more than one round of financing. Accordingly, estimates of the multinomial logit only refer to ventures obtaining a follow-on round of financing. In order to control for this selection effect, as a robustness check, we resorted to an Inverse Mill's ratio sample selection control. We ran a first stage probit model predicting the probability to obtain more than one round of financing and we derived an inverse Mills' ratio (IMR), which is the estimated value of the generalized residual. Then, to correct for the selection bias, the inverse Mills' ratio control factor was included in the second probit models predicting the probability to switch to the different types of VC investors. Estimates results, that are very similar to those obtained with the multinomial logit, are reported in Appendix B.
} 
Table 4 Definition of the variables used in the empirical analysis

Variable name

Venture quality

Incumbent $\mathrm{VC}$ reputation

Venture funding $(\operatorname{logs})$

Venture funding cumulated (logs)

Follow-on round

Number of rounds

Syndication

Syndication size

Venture age

California

Massachusetts

Distance $^{\mathrm{b}}$

Downward mismatch

Upward mismatch

State with high GDP per capita ${ }^{a}$

MSCI Index
Variable definition

Predicted probability of a successful exit (i.e. IPO) estimated from a probit regression in which the dependent variable is equal to one if the venture exited as an IPO in year t or before, and zero otherwise. The independent variables are the development stage of the venture in year $t$, the geographical location of the venture, the industry in which the venture operates, the size of the financing received by the venture until the year $t$, the number of rounds the venture received until the year $t$, and the size of the syndicate investing in the venture in year $t$

Multi-item index estimated according to Lee et al. (2011). The index is estimated as a single factor derived from a factor analysis considering different time variant measures (all based on the years prior to the focal year in which the VC invested in the specific venture as lead): the total number of portfolio companies the VC invested in; the total equity funds invested in portfolio ventures; the number of portfolio ventures taken public; VC experience (calculated as the focal year minus the year in which the specific VC fund was created). We also control for the size of the VC fund by considering the total dollar amount of funds raised, the number of individual funds raised and the total number of deals of the individual fund

Logarithm of the amount of financing received by the venture in the round

Logarithm of the total amount of financing received by the venture at the end of the observation period

Dummy variable that is equal to 1 if the focal round is a follow-on round, 0 otherwise

Number of financing rounds received by the venture

Dummy variable that is equal to 1 if the investment round is syndicated, 0 otherwise

Number of different investors in the syndicate

Venture age at the time of financing

Dummy variable that is equal to 1 if the venture is located in California, 0 otherwise

Dummy variable that is equal to 1 if the venture is located in Massachusetts, 0 otherwise

Geographic distance between the lead incumbent VC and the venture

Dummy variable that is equal to 1 if there is a downward mismatch between the stage of the venture and the stage specialization of the incumbent lead VC fund, 0 otherwise

Dummy variable that is equal to 1 if there is an upward mismatch between the stage of the venture and the stage specialization of the incumbent lead VC fund, 0 otherwise

Dummy variable that is equal to 1 if the GDP per capita of the state in which the venture is located is higher than the median, 0 otherwise

The MSCI Index is a free float-adjusted market capitalization weighted index that is designed to measure the equity market performance of developed markets 
Table 4 (continued)

\begin{tabular}{ll}
\hline Variable name & Variable definition \\
\hline Ln (incumbent fund size/round size) & $\begin{array}{c}\text { Logarithm of the ratio between the size of the specific lead VC } \\
\text { fund and the size of the next round } \\
\text { Dummy variable that is equal to } 1 \text { if the switching occurs from an } \\
\text { IVC to another IVC, } 0 \text { otherwise } \\
\text { Switching from an IVC to an IVC } \\
\text { Switching from an IVC to a GVC } \\
\text { IVC to a GVC, } 0 \text { otherwise } \\
\text { Switching from an IVC to a BVC }\end{array} \quad \begin{array}{c}\text { Dummy variable that is equal to } 1 \text { if the switching occurs from an } \\
\text { IVC to a BVC, } 0 \text { otherwise } \\
\text { Switching from an IVC to a CVC }\end{array}$ \\
$\begin{array}{c}\text { Dummy variable that is equal to } 1 \text { if the switching occurs from an } \\
\text { IVC to a CVC, } 0 \text { otherwise }\end{array}$
\end{tabular}

The Table reports the definition of the variables used in the econometric analysis

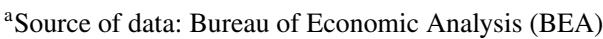

${ }^{\mathrm{b}}$ Given the latitude and longitude of the two zip codes, the distance is obtained by the following equation: distance $=\log \left(6371 * \arccos \left[\sin \left(\operatorname{lat}_{\mathrm{i}}\right) \sin \left(\mathrm{lat}_{\mathrm{j}}\right)+\cos \left(\mathrm{lat}_{\mathrm{i}}\right) \cos \left(\mathrm{lat}_{\mathrm{j}}\right) \cos \left(\left|\operatorname{long}_{\mathrm{i}}-\operatorname{long}_{\mathrm{j}}\right|\right)\right]+1\right)$

Table 5 Descriptive statistics of the variables used in the analysis

\begin{tabular}{lrrrrrr}
\hline Variable name & N. Obs. & \multicolumn{1}{l}{ Mean } & Median & \multicolumn{1}{l}{ St. Dev. } & \multicolumn{1}{l}{ Min } & \multicolumn{1}{l}{ Max } \\
\hline Venture quality & 16,846 & 0.053 & 0.040 & 0.045 & 0.000 & 0.575 \\
VC reputation & 11,746 & 0.042 & -0.288 & 1.086 & -1.086 & 6.842 \\
Venture funding (logs) & 16,846 & 1.734 & 1.792 & 1.389 & 0.000 & 7.601 \\
Venture funding cumulated (logs) & 16,846 & 1.551 & 1.550 & 1.267 & 0.000 & 7.601 \\
Follow-on round & 16,846 & 0.477 & 0.000 & 0.499 & 0.000 & 1.000 \\
Number of rounds & 16,846 & 2.364 & 2.000 & 1.811 & 1.000 & 21.000 \\
Syndication & 16,846 & 0.583 & 1.000 & 0.493 & 0.000 & 1.000 \\
Syndication size & 16,846 & 2.316 & 2.000 & 2.731 & 0.000 & 24.000 \\
Venture age & 14,439 & 0.586 & 0.333 & 0.991 & 0.000 & 15.333 \\
California & 16,846 & 0.317 & 0.000 & 0.465 & 0.000 & 1.000 \\
Massachusetts & 16,846 & 0.106 & 0.000 & 0.307 & 0.000 & 1.000 \\
Distance & 9,298 & 3.440 & 3.731 & 0.851 & 0.000 & 4.299 \\
Downward mismatch & 16,846 & 0.210 & 0.000 & 0.407 & 0.000 & 1.000 \\
Upward mismatch & 16,846 & 0.304 & 0.000 & 0.460 & 0.000 & 1.000 \\
State with high GDP per capita & 16,823 & 0.825 & 1.000 & 0.380 & 0.000 & 1.000 \\
MSCI Index & 16,846 & 1171.050 & 1196.340 & 176.801 & 824.580 & 1445.860 \\
Ln (fund size/round size) & 9,298 & 4.723 & 4.669 & 1.645 & 0.050 & 14.221 \\
Switching from an IVC to an IVC & 16,846 & 0.229 & 0.000 & 0.420 & 0.000 & 1.000 \\
Switching from an IVC to a GVC & 16,846 & 0.014 & 0.000 & 0.117 & 0.000 & 1.000 \\
Switching from an IVC to a BVC & 16,846 & 0.011 & 0.000 & 0.105 & 0.000 & 1.000 \\
Switching from an IVC to a CVC & 16,846 & 0.011 & 0.000 & 0.104 & 0.000 & 1.000 \\
\hline
\end{tabular}


to the size of the next round in order to control for the possibility that if the incumbent lead IVC is not large enough to finance the next round, the venture has no choice but to switch. In addition, we included the age of the venture at financing, a dummy variable indicating whether the round is a follow-on round, two variables indicating the mismatch between the stage of the venture and the stage specialization of the incumbent lead IVC. In particular, we considered both a "Downward" mismatch (e.g. a venture in the seed stage that is currently associated with an investor specialized in a later stage) and an "Upward" mismatch (e.g. a venture which evolves into the later stage and is currently associated with an investor specialized in the early stage). We also included the distance between the venture and the incumbent lead IVC. To measure the geographic distance between the lead IVC and the entrepreneurial venture, we obtained the latitude and longitude data for the center of each zip code from the US Census Bureau's Gazetteer and estimated the distance between the centers of the two zip codes by using the following equation:

$$
\begin{aligned}
\text { distance }= & \log \left(6 3 7 1 * \operatorname { a r c c o s } \left[\sin \left(\operatorname{lat}_{\mathrm{i}}\right) \sin \left(\mathrm{lat}_{\mathrm{j}}\right)\right.\right. \\
& \left.\left.+\cos \left(\operatorname{lat}_{\mathrm{i}}\right) \cos \left(\operatorname{lat}_{\mathrm{j}}\right) \cos \left(\left|\operatorname{long}_{\mathrm{i}}-\operatorname{long}_{\mathrm{j}}\right|\right)\right]+1\right),
\end{aligned}
$$

where latitude (lat) and longitude (long) are measured in radians.Moreover, we also controlled for the economic conditions of the state in which the venture is located and for the state of the stock markets by including a dummy variable State with high GDP per capita and the MSCI Index, described in Table 4. Finally, we included year and geographical location dummies in all the model specifications.

The results from the multinomial logit estimates are shown in Table 6. The different columns refer to the different typologies of switching (from an IVC to another IVC in column I, from an IVC to a GVC in column II, from an IVC to a BVC in column III and from an IVC to a CVC in column IV).

It is important to observe that, in order to discuss the effects of perceived venture quality and incumbent $\mathrm{VC}$ reputation on the probability of switching, according to our research hypotheses, it is necessary to take into account the presence of their interaction term. We thus need to estimate the marginal effect of perceived venture quality at the different values of the incumbent VC reputation and vice versa, the marginal effect of the incumbent $\mathrm{VC}$ reputation at the different levels of perceived venture quality. The standard error of the marginal effects is calculated at the means of the regressors using the delta method (Greene 2008, pp. 68-70). The magnitude and significance of the marginal effects are represented in Tables 7, 8, Panel A for perceived venture quality and Panel B for incumbent VC reputation, respectively.

Panel A of Table 7 shows the marginal effects of perceived venture quality in the different types of switching according to the different levels of the incumbent VC reputation. Looking at the switching from an IVC to another IVC (first column), results are in accordance with Cumming and Dai (2013), confirming that the higher 


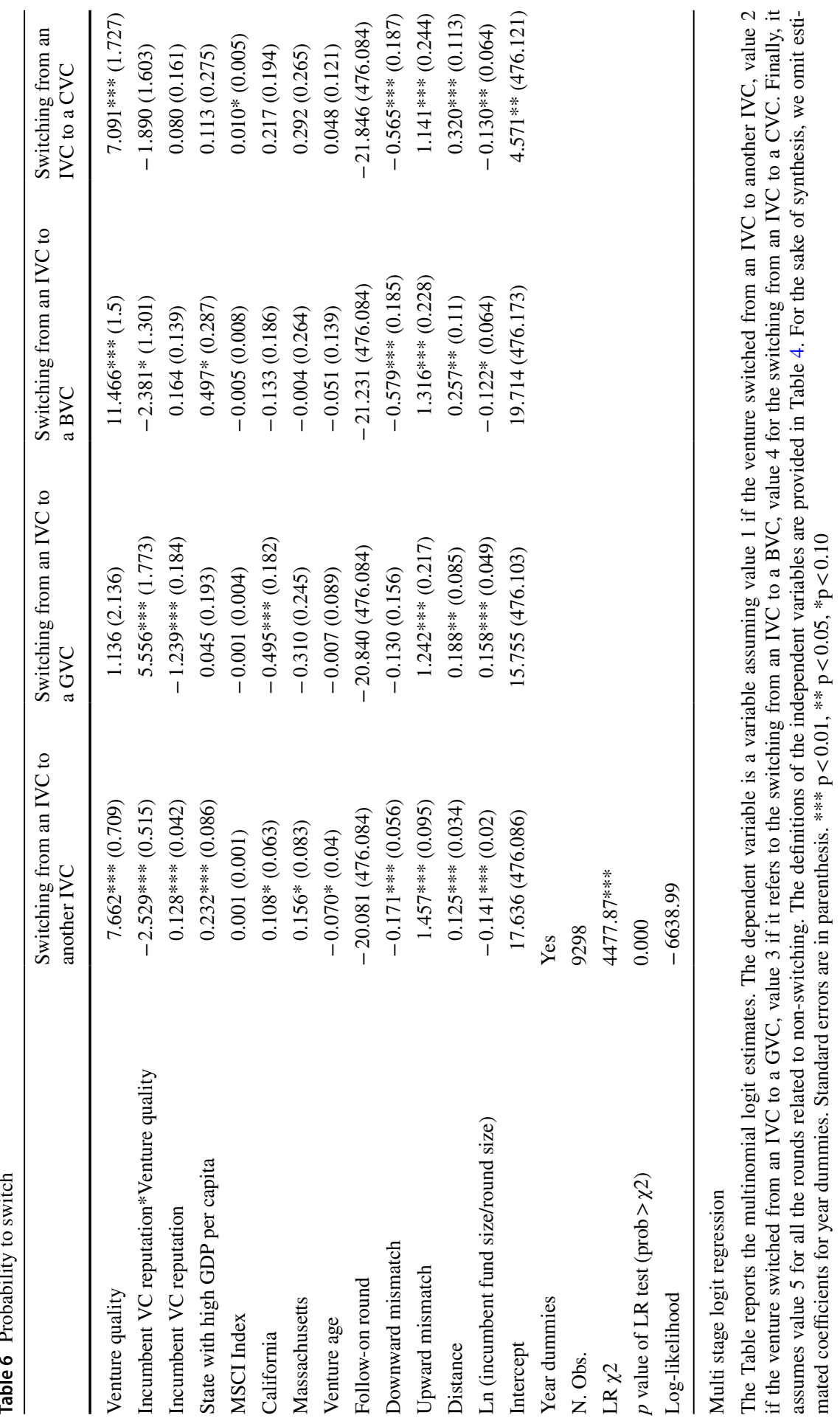




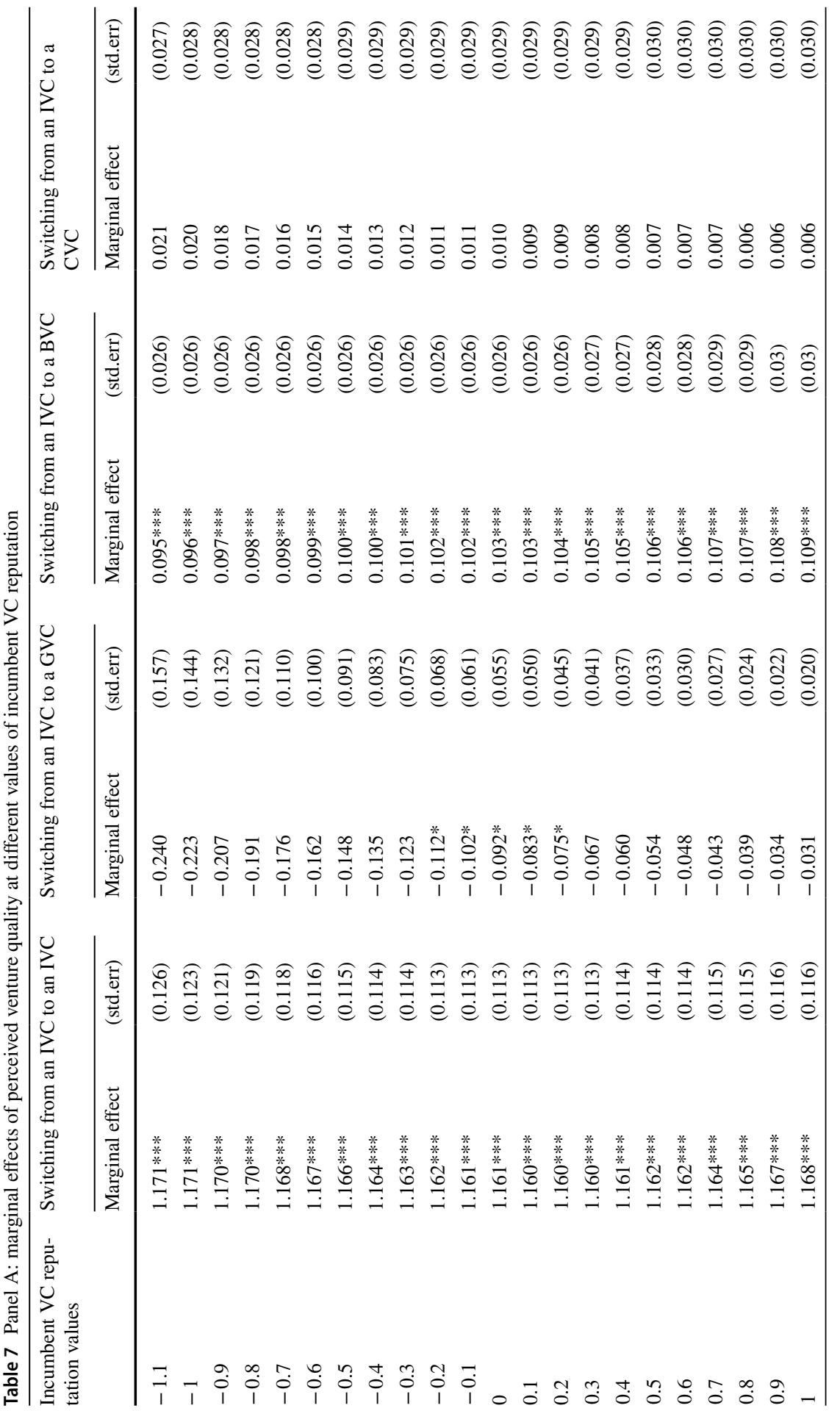




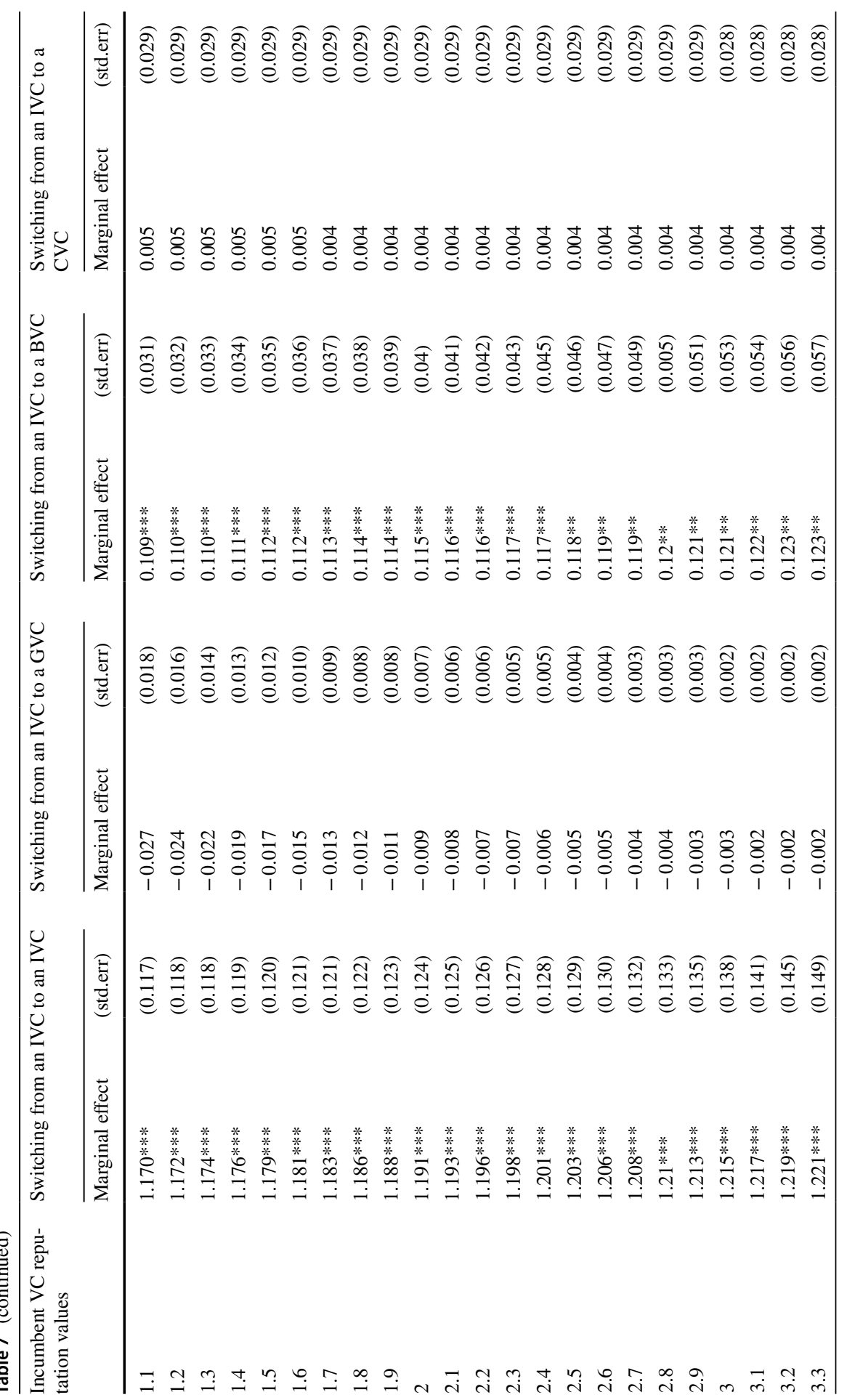




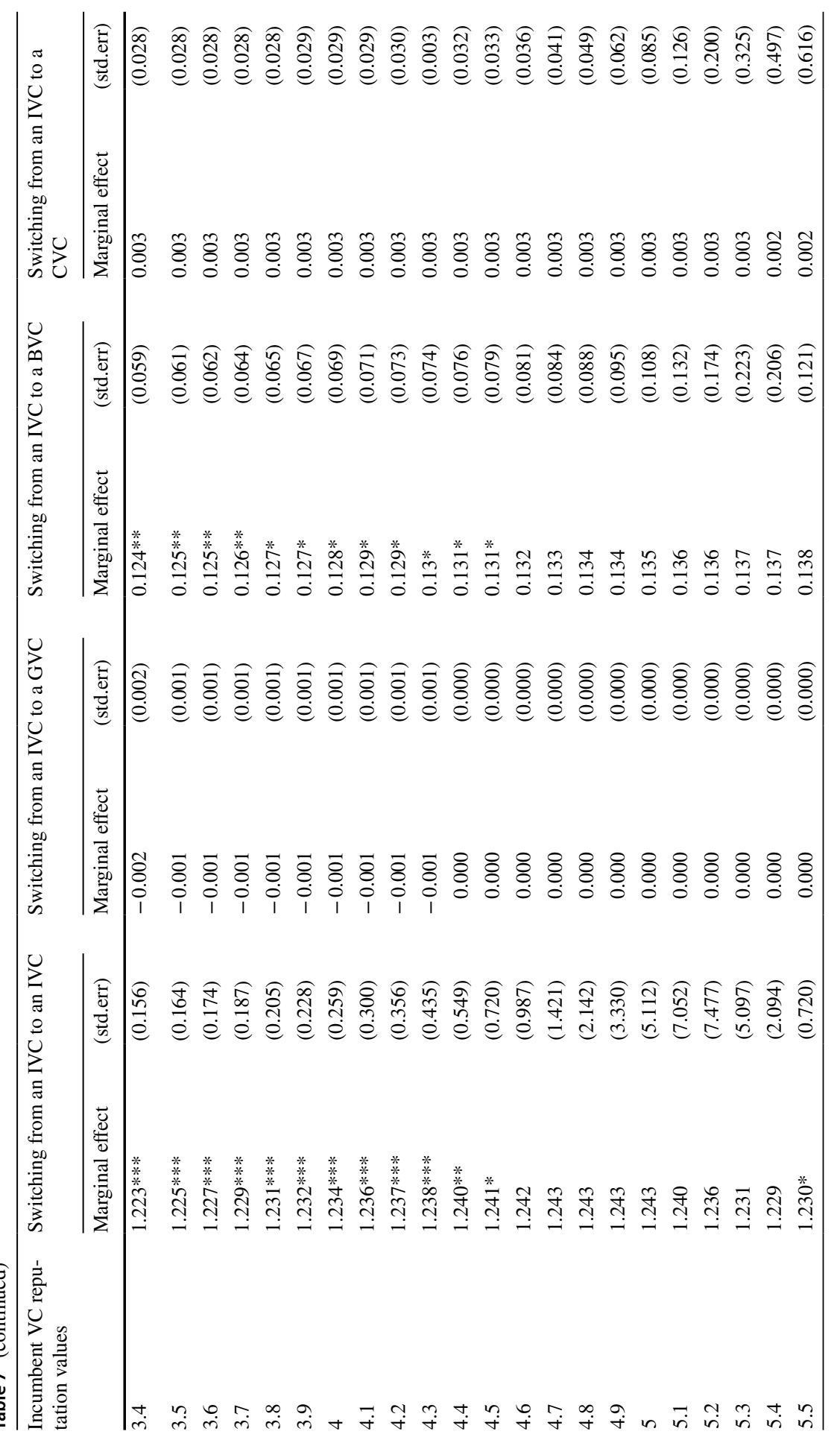




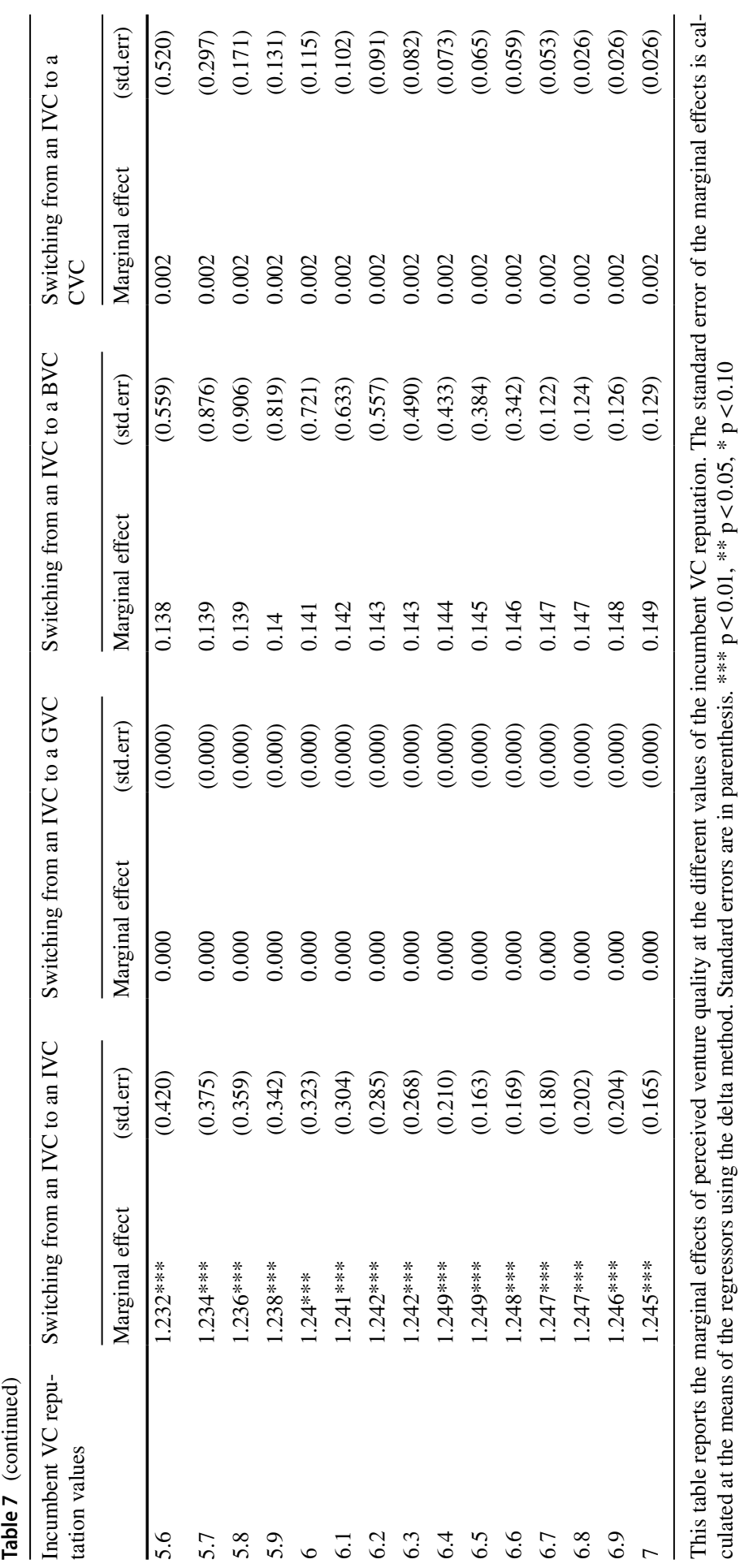




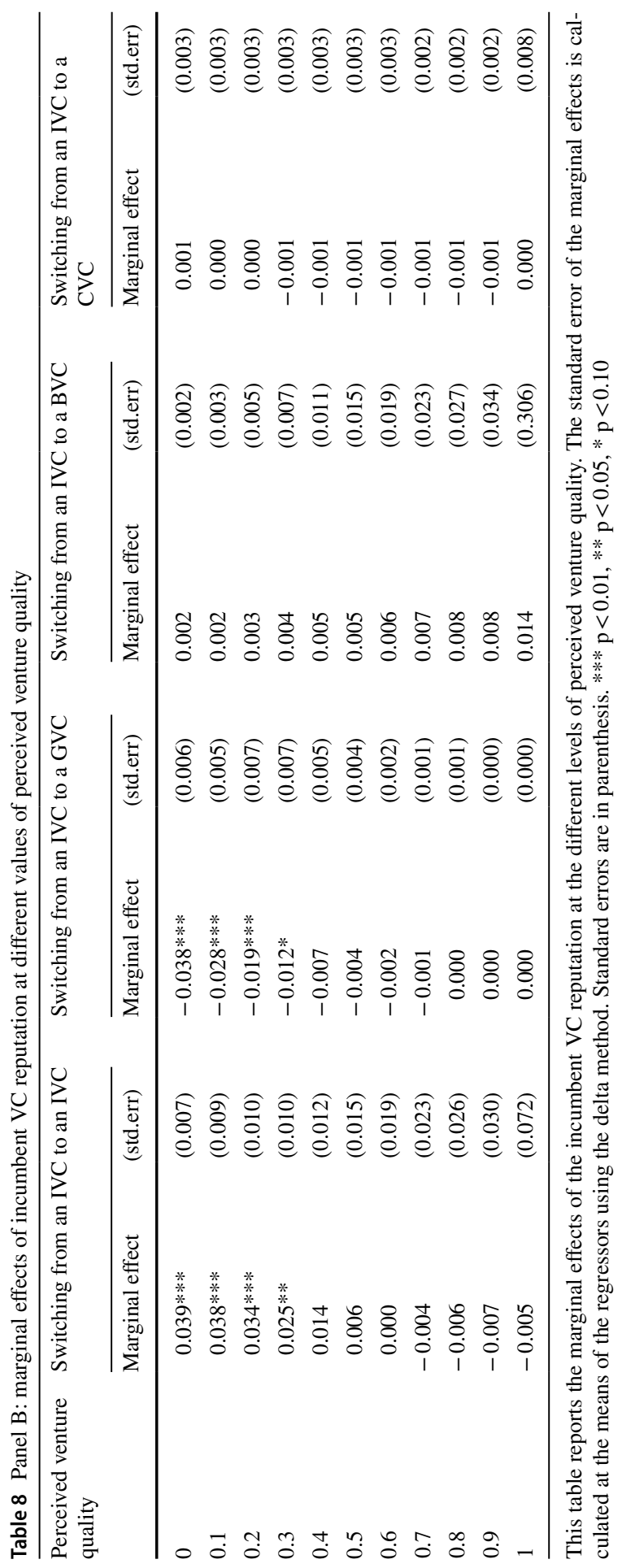


is the perceived quality of the venture, the higher is the probability to switch from an IVC to another IVC (independently of the reputation of the incumbent lead investor). In fact, the marginal effects of perceived venture quality are always positive and significant, whatever the value of the incumbent VC reputation. ${ }^{14}$ Conversely, the incumbent VC reputation has a positive effect on the probability to switch to another IVC only at low values of perceived venture quality as confirmed by looking at the marginal effects reported in the first column of Panel B of Table 8: the marginal effects are positive and significantly different from zero only for low values of perceived venture quality.

According to the second column of Panel A of Table 7, the perceived quality of a venture negatively influences the probability to switch from an IVC to a GVC at low values of the incumbent IVC reputation: the lower is the venture's perceived quality, the higher is the probability to switch from an IVC to a GVC. This effect is significant the lower is the reputation of the incumbent IVCThe previous result is confirmed if one looks at the marginal effects of the incumbent VC reputation in Panel B of Table 8. Results suggest that the lower is the reputation of the incumbent IVC, the higher is the probability to switch to a GVC and this effect is significant for low perceived quality ventures. This result is in line with what found by Abrardi et al. (2018). This evidence confirms that GVCs intervene in the VC market to fill the "equity gap" generated by IVCs, being less interested than IVCs in the perceived quality of the selected ventures. It follows that GVCs select ventures whose quality has been downwardly revised and that cannot even take advantage of the signaling effect to the VC market deriving from being associated with a reputable IVC.

Concerning the switching from an IVC to a BVC, the perceived quality of the venture has a positive effect on the probability to switch when the reputation of the incumbent IVC is not high. Higher quality ventures have a higher probability to switch from an IVC to a BVC but, contrary to the switching from an IVC to another IVC, this effect is not independent of the reputation of the incumbent IVC. In other words, it seems that venture quality plays a significant role when the reputation of the incumbent IVC is not high. Instead, if the reputation of the incumbent IVC is high, venture quality is not significant anymore. Contrary to IVCs, BVCs seem to assign a relevant value to venture quality only when the reputation of the IVC is low. Conversely, at higher levels of the incumbent IVC reputation, this latter becomes an alternative indicator of the worthiness of the investment and venture quality loses importance. Finally, in line with our expectations, neither venture quality nor the reputation of the incumbent IVC matter when a switching takes place from an IVC to a CVC.

Among the control variables, results reported in Tables 6 indicate that the switching from an IVC to another IVC is significantly more likely to occur for ventures located in states with high GDP per capita, while the switching from an IVC to a GVC is less likely in California. We also find that the size of the incumbent IVC

\footnotetext{
14 The marginal effect of venture quality is not significant for a short interval of incumbent VC reputation, ranging from 4.6 to 5.4 . Only the $0.219 \%$ of observations in our sample assume values in this range of non-significance.
} 
Table 9 Impact of switching

\begin{tabular}{|c|c|c|c|c|}
\hline & \multicolumn{2}{|l|}{ Probability of IPO } & \multicolumn{2}{|l|}{ Valuation } \\
\hline & Model 1 & Model 2 & Model 1 & Model 2 \\
\hline Switching to an IVC & $0.152 * * *(0.05)$ & $0.138 * *(0.06)$ & $-0.005(0.06)$ & $-0.050 .07)$ \\
\hline Switching to a GVC & $-0.229(0.27)$ & $-0.244(0.27)$ & $0.126(0.21)$ & $0.053(0.22)$ \\
\hline Switching to a BVC & $0.142(0.25)$ & $0.124(0.26)$ & $0.125(0.17)$ & $0.033(0.2)$ \\
\hline Switching to a CVC & $0.611 * *(0.25)$ & $0.594 * *(0.25)$ & & \\
\hline $\begin{array}{l}\text { Venture funding cumulated } \\
(\operatorname{logs})\end{array}$ & $0.239 * * *(0.03)$ & $0.228 * * *(0.03)$ & & \\
\hline Number of rounds & $-0.106 * * *(0.02)$ & $-0.098 * * *(0.02)$ & & \\
\hline Valuation of previous round & & & $0.713^{* * *}(0.04)$ & $0.699 * * *(0.04)$ \\
\hline VC reputation & & & $0.033(0.02)$ & $0.04 * *(0.02)$ \\
\hline Massachussets & $0.06(0.08)$ & $0.0570 .08)$ & $0.146 *(0.08)$ & $0.14 *(0.08)$ \\
\hline California & $0.255^{* * *}(0.06)$ & $0.245 * * *(0.06)$ & $0.111(0.07)$ & $0.091(0.07)$ \\
\hline Syndication size & $0.037 * * *(0.01)$ & $0.034 * * *(0.01)$ & $0.052 * * *(0.01)$ & $0.04 * * *(0.01)$ \\
\hline Inverse Mill's Ratio & & $0.118(0.12)$ & & $0.358 * *(0.15)$ \\
\hline Intercept & $-2.178 * * *(0.35)$ & $-2.072 * * *(0.36)$ & $0.827 * * *(0.21)$ & $1.177 * * *(0.25)$ \\
\hline $\mathrm{N}$ & 7366 & 7366 & 491 & 491 \\
\hline
\end{tabular}

The Table reports estimates of the impact of switching on the probability of IPO (first two columns) and on the valuation received (last two columns). Standard errors are in parenthesis. $* * * \mathrm{p}<0.01, * *$ $\mathrm{p}<0.05, * \mathrm{p}<0.10$

relative to the size of the next round is negatively associated with the probability of switching to another IVC and to a BVC, while it is positively related to the probability to switch to a GVC. This finding suggests that the incumbent IVC's capacity to provide enough funding to the venture is an important determinant in the decision to choose a new IVC or a BVC, while the opposite is true if a new GVC makes the investment. Ventures are more likely to switch to another IVC if they are backed by a small IVC, because they search for a similar investor endowed with more resources to finance their growth. This motivation does not drive the decision to switch toward a GVC: in fact, the larger is the incumbent IVC, the higher is the probability to switch to a GVC.

The geographical proximity between entrepreneurial ventures and lead IVCs seems to affect the switching dynamics among all types of $\mathrm{VC}$ investors. In fact, the higher is the distance between the venture and its incumbent IVC, the higher is the probability to switch to another VC. Also, the divergence between the investment focus of the incumbent IVC investor and the current stage of the venture is significantly associated with the probability of switching. More in detail, the presence of a downward mismatch decreases the probability to switch to all types of investors, with the exception of the switching to a GVC. Conversely, the presence of an upward mismatch increases the probability to switch from an IVC to another VC investor, whatever type it is. 
As a further empirical evidence, we examined the impact of switching to a different type of investor on the probability to exit through an IPO as a proxy of venture performance. Results of the probit model, reported in the first column of Table 9, indicate that only the switching from an IVC to another IVC or to a CVC increases the probability to exit through an IPO. Instead, we do not find a significant impact of the switching dynamic neither from an IVC towards a GVC nor to a BVC. As far as control variables are concerned, we find that the probability of successful exit increases with syndicate size and with the amount of financing received in the round. As documented in Sahlman (1990) and Gompers (1995), deal syndication is an important tool that VCs utilize in managing investment risk. By syndicating investments, VCs are able to share the risks of a project with other investors, thereby increasing the probability of exit success. Also, the capital amounts VCs disburse in the rounds of financing are proxies for individual estimates of the option value to abandon the investment, and by implication, the probability of a successful exit (Obrimah and Prakash 2010).

Table 9 (second column) also reports the estimates of the impact of the different types of switching on the valuation (in 1985 millions \$) received in a financing round. In particular, we estimated a random effect model on the valuation (in logs) provided to the entrepreneurial venture at the time of financing. We do not obtain significant results that firms switching from an IVC to other types of VCs obtain higher valuations.

\section{Discussion}

While there is a good deal of scholarly works examining the determinants of the matching between entrepreneurs and investors in the VC market (Hsu 2004; Sørensen 2007), limited attention has been provided on how the relationship between the two parties evolves. In particular, little research we are aware of has attempted to explore the dynamics behind the switching of lead VC investors in the light of the type of the VCs involved.

The VC industry is populated by an increasingly diverse set of investors, showing different objectives, risk propensity, expected returns and investment strategies. Both the selection process of target ventures and their subsequent management and abandonment options are affected by the institutional characteristics of VC investors. To date, we know remarkably little about how different organizational forms of VCs affect switching dynamics and to what extent a change in lead investor of a different type impacts upon the performance of VC-backed ventures. Our paper represents a first attempt aimed at filling this gap.

In this paper we have provided more fine-grained insights than hitherto about what affects VC switching, looking at different types of VCs: IVCs, GVCs, BVCs, CVCs. For this purpose, we have used a sample of 16,846 rounds of VC financing in 12,193 entrepreneurial ventures between 1998 and 2010 in the US, 9298 of which are follow-on rounds. Out of these, 4462 rounds have been characterized by the switching phenomenon, involving 2553 ventures.

Results show that the higher is the perceived quality of the venture, the higher is the probability to switch from an IVC to another IVC (independently of the 
reputation of the incumbent lead investor). In addition, the lower is the perceived quality of the entrepreneurial venture and the lower is the reputation of the incumbent lead IVC, the higher is the likelihood to rematch with a GVC. This evidence highlights that GVCs intervene to compensate a market failure (or an "equity gap"), by selecting ventures from less reputable IVCs whose returns might not completely satisfy private investors. When the switching dynamics from an IVC to a BVC are considered, we find that the venture's perceived quality has a positive effect on the probability to switch to a BVC when the reputation of the incumbent IVC is not high. Instead, if the reputation of the incumbent IVC is high, venture quality loses importance for the new BVC investor. Finally, neither the quality of a venture nor the reputation of the incumbent IVC matter when a switching takes place from an IVC to a CVC. We also find that the probability of successful exit increases when the switching occurs from an IVC to a new lead IVC or to a CVC. Instead, we do not find a significant impact of the switching dynamic towards a GVC or a BVC on the probability that a venture is brought to IPO.

We argue that this evidence is compatible with the different objective functions and value added services provided by different types of investors. Both IVCs and CVCs assist portfolio companies by providing value-added services and by leveraging corporate resources, this contributing to enhance the growth of the ventures from which they later exit via an initial public offering. On the contrary, GVCs pursue other goals that have priority over the maximization of the economic return on investment and BVCs have less pressure to maximize returns and provide less governance and give less advice to investees than IVCs.

Our findings offer several practical implications for both VC investors and entrepreneurs. Contrary to an IVC, a venture's perceived quality is not of primary interest for an entrant GVC, because this latter is much more concerned about the venture's potential in realizing social returns. However, the quality of a venture is substantially regarded by a BVC, which can deviate its attention from venture quality only in case the incumbent IVC is highly reputable.

From the perspective of the recipient of venture capital, our results suggest that entrepreneurs should carefully consider the type of the VC to be associated with, in order to gain the most of advantage from switching. For example, a venture aiming at increasing the availability and quantity of credit should target a BVC, while a venture that aims at enlarging its access to complementary assets and international product markets might prefer to switch to a CVC. Also, the economic benefits to an entrepreneurial venture of being associated with a GVC are large. The GVC would exert a certification function towards other private sources of capital that might otherwise have been out of reach for the venture. However, ventures should consider that the probability of a successful exit is only increased if they switch from an IVC to another IVC or to a CVC. Consequently, entrepreneurs will see substantive benefits down the road in terms of IPO likelihood only if a continuity in the support provided by IVC or a switching to CVC investors is envisaged.

The study has some clear limitations that suggest avenues for further research. The most relevant limitation involves the study's typology of data. Data on VCs and VC-backed firms are limited in richness of information because they are derived from commercial databases. For example, we cannot distinguish the case in which 
the new lead investor joins the existing investor (which still participates in the new round) from the case in which the new VC replaces the current investor (which is not participating in the new round). This issue could be carefully considered in future research. An additional limitation concerns the fact that we have to infer VC investors' motivations from proxies of their reputation and that we can just approximate venture quality with its predicted probability of a successful exit. Data limitations also prevent us from examining venture quality at different points in time. This leaves open the possibility that both VC reputation and venture quality could be better measured in the presence of richer data sources. Future research should strive to obtain detailed information on the organizational background, investment strategies and managerial competences of VC funds, in order to provide a more refined measure of VC reputation. In addition, scholars might usefully examine further measures of venture quality, using accounting data to evaluate ventures' financial performance, and exploring the several dimensions of the entrepreneurial activity (e.g. innovation and R\&D expenditures, investment practices, export activities). Another limitation of our work is that we have examined the reasons for switching by looking uniquely at the roles played by $\mathrm{VC}$ reputation and venture quality. However, there might be other reasons to explore. Future research could use finer-grained methods, such as qualitative research (direct interviews or surveys) or controlled laboratory experiments to rule out alternative explanations. VC firms' decisions to abandon or to take on ventures may be motivated by resource dependencies, institutional and competitive pressures, industry conditions, technological turmoil, and changes in market conditions. Differences across institutional types of VCs in the way they respond to such challenges may affect switching dynamics and ultimately the performance of investee ventures.

As the field moves from infancy to what we hope will be a certain level of growth, some additional questions might be asked and investigated. What are the implications that switching lead VC investor has on syndicated deals and on VC network relationships? How does switching affect the organizational structure, investment strategy and managerial incentives of entrepreneurial ventures? Does switching occur more often in bullish or bearish states of financial markets? Does switching display different effects on ventures' performance in different industrial fields and in different national contexts? What are the implications for VC-backed ventures of multiple switching? In general, the $\mathrm{VC}$ competitive arena, the characteristics of VC network relationships, the industry structure and the state of the economy are assumed to account for many of the variations in switching behavior, but remain issues that deserve further exploration. The understanding of the interconnections that exist between a VC firm's strategies and managerial incentives, the characteristics of the ventures, the VC network relationships and the institutional, industrial and economic environment needs to be further elaborated and is rich in potential for future research. We have only begun to uncover the intricacies of those relationships.

\section{Appendix A}

See Table 10 here. 


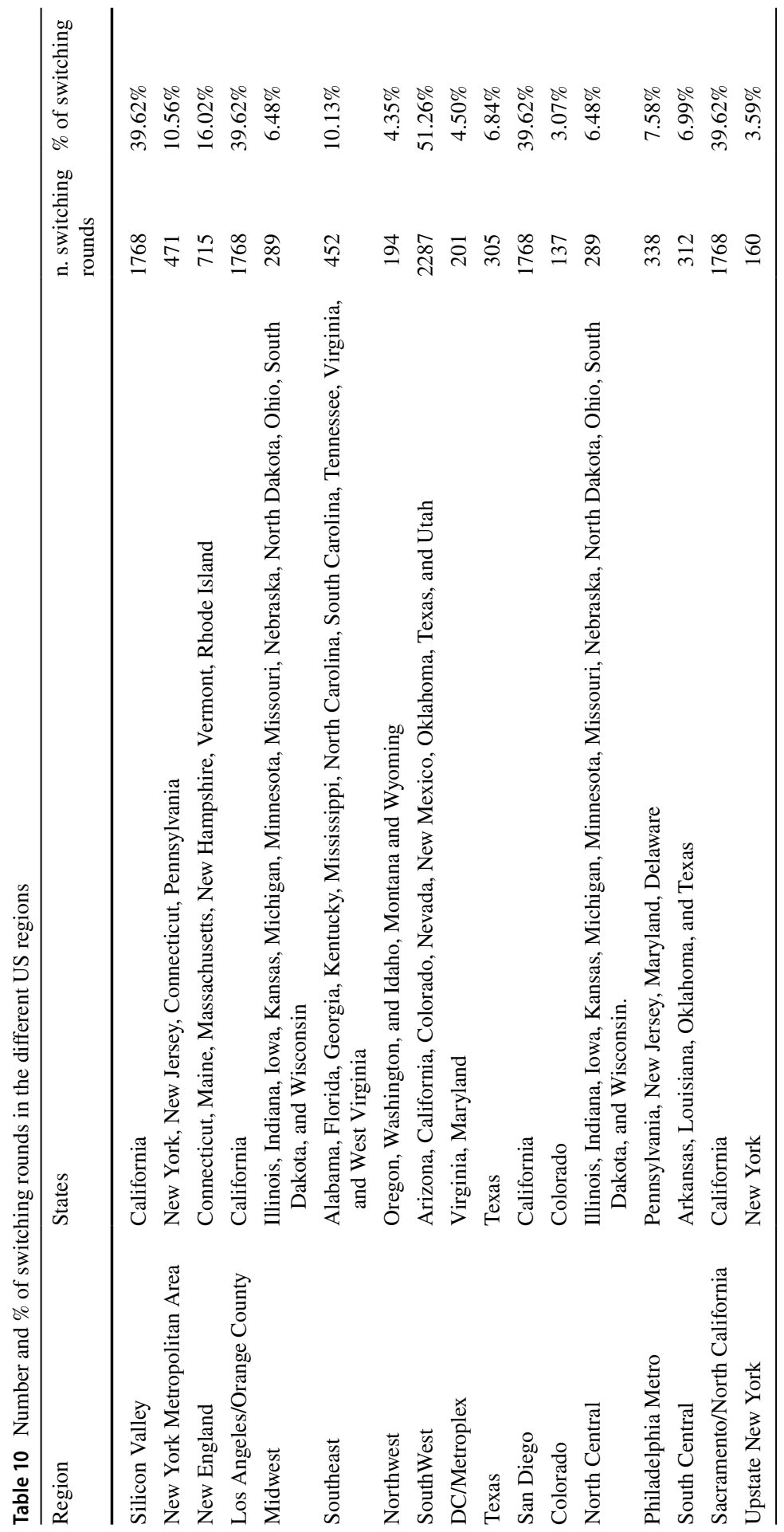




\section{Appendix B}

Tables 11 and 12 illustrate the results of a sample selection model based on the Heckman two-stage framework. The model consists of two simultaneous equations to distinguish between the determinants of successfully obtaining more than one round of financing in the sample period and those influencing the occurrence of the switching event. In the first step, the binary dependent variable is a dummy which is equal to one if the venture has successfully obtained more than one round of financing during the sample period. The independent variables include: a dummy indicating the stage of the venture at the time of the financing round (i.e. Acquisition/Buyout, Early stage, Later stage, Other stage), the geographical location of the venture (i.e. in particular, two dummies indicate whether the venture is located in California or Massachusetts), a dummy variable which is equal to 1 if the deal is syndicated, the amount of financing received by the venture in the round (in logarithms), industry and year controls.

In the second step, the probability of switching was regressed on a set of variables concerning the reputation of the incumbent lead IVC, the perceived quality of the entrepreneurial venture, the interaction between the two variables and the IMR previously estimated.

See Tables 11, 12 here.

Table 11 Probability to receive more than one round of financing

\begin{tabular}{|c|c|c|c|c|}
\hline & $\begin{array}{l}\text { Switching from } \\
\text { an IVC to an IVC }\end{array}$ & $\begin{array}{l}\text { Switching from } \\
\text { an IVC to a GVC }\end{array}$ & $\begin{array}{l}\text { Switching from } \\
\text { an IVC to a BVC }\end{array}$ & $\begin{array}{l}\text { Switching from an } \\
\text { IVC to a CVC }\end{array}$ \\
\hline California & $0.182 * * *(0.03)$ & $0.181 * * *(0.03)$ & $0.181 * * *(0.03)$ & $0.181 * * *(0.03)$ \\
\hline Massachusetts & $0.406 * * *(0.04)$ & $0.405^{* * *}(0.04)$ & $0.404 * * *(0.04)$ & $0.404 * * *(0.04)$ \\
\hline Syndication & $0.819 * * *(0.02)$ & $0.813 * * *(0.02)$ & $0.809 * * *(0.02)$ & $0.810 * * *(0.02)$ \\
\hline Venture funding (logs) & $0.246 * * *(0.01)$ & $0.252 * * *(0.01)$ & $0.252 * * *(0.01)$ & $0.254 * * *(0.01)$ \\
\hline Intercept & $-3.340 * * *(0.39)$ & $-3.165 * * *(0.37)$ & $-3.107 * * *(0.36)$ & $-3.257 * * *(0.38)$ \\
\hline Year dummies & Yes & Yes & Yes & Yes \\
\hline Venture stage dummies & Yes & Yes & Yes & Yes \\
\hline Industry dummies & Yes & Yes & Yes & Yes \\
\hline N. Obs. & 16,846 & 16,846 & 16,846 & 16,846 \\
\hline
\end{tabular}

First-stage probit regression

The dependent variable is whether the venture has received more than one round of successful financing during the sample period. The definitions of the independent variables are provided in Table 4 . For the sake of synthesis, we omit estimated coefficients for year, venture stage and industry dummies. Standard errors are in parenthesis. $* * * \mathrm{p}<0.01, * * \mathrm{p}<0.05, * \mathrm{p}<0.10$ 


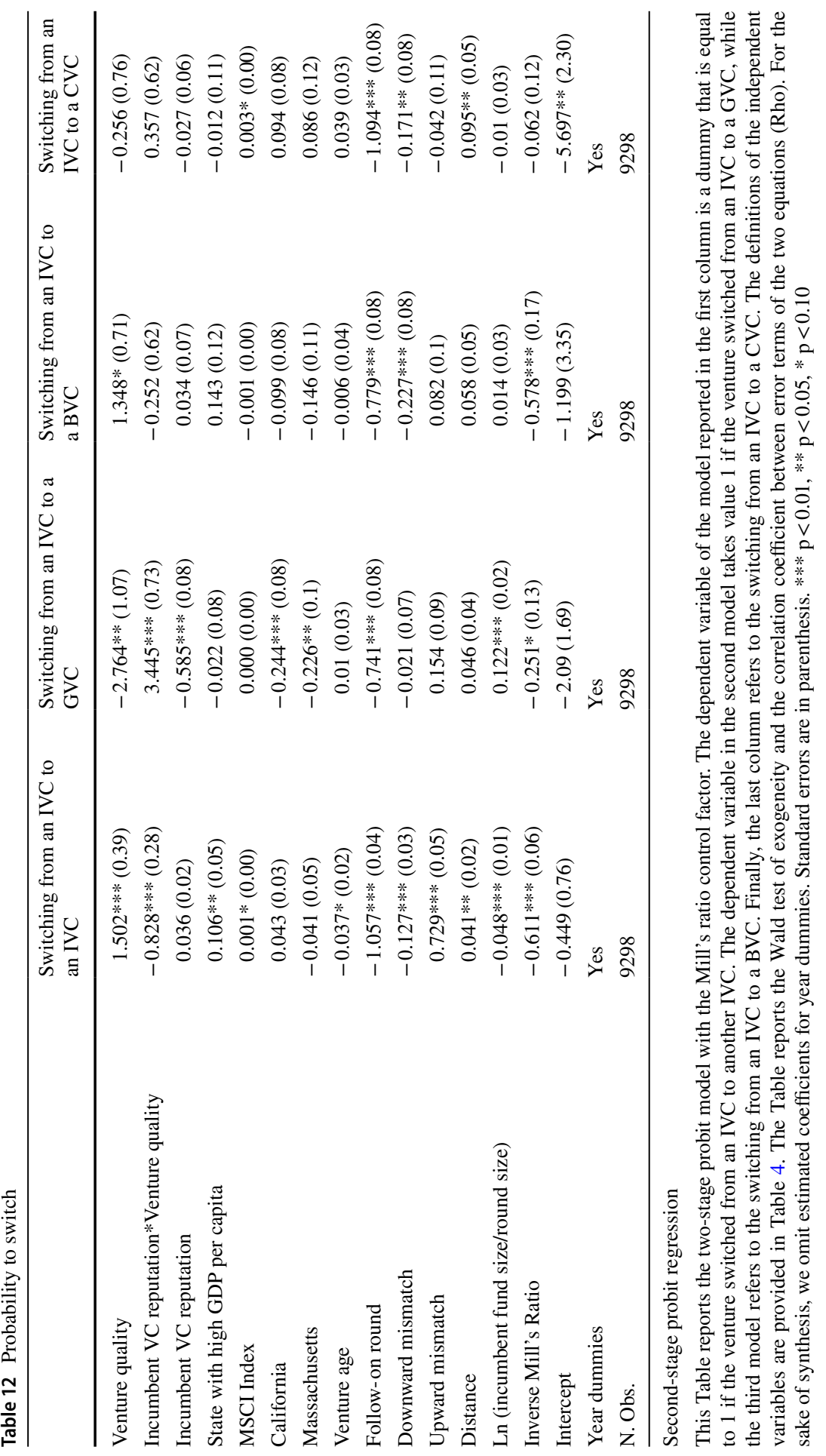




\section{References}

Abrardi, L., Croce, A., \& Ughetto, E. (2018). The dynamics of switching between governmental and independent venture capitalists: Theory and evidence. Small Business Economics. https://doi. org/10.1007/s11187-018-0047-z.

Afful-Dadzie, E., \& Afful-Dadzie, A. (2016). A decision making model for selecting start-up businesses in a government venture capital scheme. Management Decision, 54(3), 714-734.

Andrieu, G. (2013). The impact of the affiliation of venture capital firms: A survey. Journal of Economic Surveys, 27(2), 234-246.

Andrieu, G., \& Groh, A. P. (2012). Entrepreneurs' financing choice between independent and bank-affiliated venture capital firms. Journal of Corporate Finance, 18(5), 1143-1167.

Baum, J. A. C., \& Silverman, B. S. (2004). Picking winners or building them? Alliance, intellectual, and human capital as selection criteria in venture financing and performance of biotechnology start-ups. Journal of Business Venturing, 19(3), 411-436.

Becker, G. S. (1983). A theory of competition among pressure groups for political influence. Quarterly Journal of Economics, 98(3), 371-400.

Bertoni, F., Colombo, M., \& Quas, A. (2015). The patterns of venture capital investment in Europe. Small Business Economics, 45, 543-560.

Bertoni, F., D'Adda, D., \& Grilli, L. (2016). Cherry-picking or frog-kissing? A theoretical analysis of how investors select entrepreneurial ventures in thin venture capital markets. Small Business Economics, 46, 391-405.

Brander, J. A., Du, Q., \& Hellmann, T. F. (2015). The effects of government-sponsored venture capital: International evidence. Review of Finance, 19, 571-618.

Buzzacchi, L., Scellato, G., \& Ughetto, E. (2013). The investment strategies of publicly sponsored venture capital funds. Journal of Banking \& Finance, 37(3), 707-716.

Chemmanur, T. J., Loutskina, E., \& Tian, X. (2014). Corporate venture capital, value creation, and innovation. Review of Financial Studies, 27, 2434-2473.

Colombo, M., \& Murtinu, S. (2017). Venture capital investments in Europe and portfolio firms' economic performance: Independent versus corporate investors. Journal of Economics and Management Strategy, 26(1), 35-66.

Croce, A., D’Adda, D., \& Ughetto, E. (2015). Venture capital financing and the financial distress risk of portfolio firms. How independent and bank-affiliated investors differ. Small Business Economics: An Entrepreneurship Journal, 44(1), 189-206.

Cumming, D. J., \& Dai, N. (2013). Why do entrepreneurs switch lead venture capitalists? Entrepreneurship: Theory and Practice, 37(5), 999-1017.

Cumming, D. J., Grilli, L., \& Murtinu, S. (2017). Governmental and independent venture capital investments in Europe: a firm-level performance analysis. Journal of Corporate Finance, 42, 439-459.

Cumming, D. J., \& MacIntosh, J. G. (2001). Venture capital investment duration in Canada and the United States. Journal of Multinational Financial Management, 11, 445-463.

Devenow, A., \& Welch, I. (1996). Rational herding in financial economics. European Economic Review, 40(3-5), 603-615.

Dushnitsky, G., \& Lenox, M. J. (2005). When do incumbents learn from entrepreneurial ventures? Corporate venture capital and investing firm innovation rates. Research Policy, 34, 615-639.

Fitza, M., Matusik, S. F., \& Mosakowski, E. (2009). Do VCs matter? The importance of owners on performance variance in start-up firms. Strategic Management Journal, 30, 387-404.

Fried, V. H., \& Hisrich, R. D. (1994). Toward a model of venture capital investment decision making. Financial Management, 23(3), 28-37.

Fulghieri, P., \& Sevilir, M. (2009). Organization and financing of innovation, and the choice between corporate and independent venture capital. Journal of Financial and Quantitative Analysis, 44, 1291-1321.

Gompers, P. A. (1995). Optimal investment, monitoring, and the staging of venture capital. Journal of Finance, 50, 1461-1489.

Gompers, P. A., \& Lerner, J. (1998). What drives venture capital fundraising? Brookings Papers on Economic Activity, Microeconomics, 1, 149-192.

Gompers, P. A., \& Lerner, J. (2000). The venture capital cycle. Cambridge: MIT Press.

Gompers, P. A., \& Lerner, J. (2001). The venture capital revolution. Journal of Economic Perspectives, 15(2), 145-168. 
Greene, W. H. (2008). Econometric analysis (6th ed.). Upper Saddle River: Pearson Prentice Hall.

Grilli, L., \& Murtinu, S. (2014). Government, venture capital and the growth of European high-tech entrepreneurial firms. Reserch Policy, 43, 1523-1543.

Grilli, L., \& Murtinu, S. (2015). New technology-based firms in Europe: market penetration, public venture capital, and timing of investment. Industrial and Corporate Change, 24(5), 1109-1148.

$\mathrm{Gu}$, Q., \& Lu, X. (2014). Unraveling the mechanisms of reputation and alliance formation: A study of venture capital syndication in China. Strategic Management Journal, 35, 739-750.

Guerini, M., \& Quas, A. (2016). Governmental venture capital in Europe: Screening and certification. Journal of Business Venturing, 31, 175-195.

Hellmann, T. (2002). A theory of strategic venture investing. Journal of Financial Economics, 64, $285-314$.

Hellmann, T., Lindsey, L., \& Puri, M. (2008). Building relationships early: Banks in venture capital. The Review of Financial Studies, 21(2), 513-541.

Hellmann, T., \& Puri, M. (2002). Venture capital and the professionalization of start-up firms: Empirical evidence. Journal of Finance, 57(1), 169-197.

Hochberg, Y. V., Ljungqvist, A., \& Yang, L. (2007). Whom you know matters: Venture capital networks and investment performance. Journal of Finance, 62(1), 251-301.

Hsu, D. H. (2004). What do entrepreneurs pay for venture capital affiliation? Journal of Finance, 59, 1805-1844.

Jääskeläinen, M., Maula, M., \& Murray, G. (2007). Profit distribution and compensation structures in publicly and privately funded hybrid venture capital funds. Research Policy, 36, 913-929.

Kaplan, S. N., \& Strömberg, P. (2004). Characteristics, contracts and actions: evidence from venture capitalists analyses. Journal of Finance, 59, 2177-2210.

Kolympiris, C., Hoenen, S., \& Kalaitzandonakes, N. (2018). Geographic distance between venture capitalists and target firms and the value of quality signals. Industrial and Corporate Change, 27(1), 189-220.

Lee, P. M., Pollock, T. G., \& Jin, K. (2011). The contingent value of venture capitalist reputation. Strategic Organization, 9(1), 33-69.

Lee, P. M., \& Wahal, S. (2004). Grandstanding, certification and the underpricing of venture capital backed IPOs. Journal of Financial Economics, 73, 375-407.

Leleux, B., \& Surlemont, B. (2003). Public versus private venture capital: seeding or crowding out? A pan-European analysis. Journal of Business Venturing, 18, 81-104.

Lerner, J. (2002). When bureaucrats meet entrepreneurs: The design of effective 'public venture capital' programmes. Economic Journal, 112(477), F73-F84.

Lin, S.-J., \& Lee, J.-R. (2011). Configuring a corporate venturing portfolio to create growth value: within-portfolio diversity and strategic linkage. Journal of Business Venturing, 26, 489-503.

Manigart, S., De Waele, K., Wright, M., Robbie, K., Desbrieres, P., Sapienza, H. J., et al. (2002). Determinants of required return in venture capital investments: A five-country study. Journal of Business Venturing, 17(4), 291-312.

Nahata, R. (2008). Venture capital reputation and investment performance. Journal of Financial Economics, 90, 127-151.

Norton, E., \& Tenenbaum, B. (1993). Specialization versus diversification as a venture capital investment strategy. Journal of Business Venturing, 8, 431-442.

Obrimah, O. A., \& Prakash, P. (2010). Performance reversals and attitudes towards risk in the venture capital (VC) market. Journal of Economics and Business, 62, 537-561.

Park, H. D., \& Steensma, H. K. (2012). When does corporate venture capital add value? Strategic Management Journal, 33, 1-22.

Park, H. D., \& Steensma, H. K. (2013). The selection and nurturing effects of corporate investors on new venture Innovativeness. Strategic Entrepreneurship Journal, 7, 311-330.

Sahlman, W. A. (1990). The structure and governance of venture-capital organizations. Journal of Financial Economics, 27(2), 473-521.

Shepherd, D. A. (1999). Venture capitalists' assessment of new venture survival. Management Science, 45(5), 624-632.

Sørensen, M. (2007). How smart is smart money? A two-sided matching model of venture capital. Journal of Finance, 62, 2725-2762.

Souitaris, V., \& Zerbinati, S. (2014). How do corporate venture capitalists do deals? An exploration of corporate investment practices. Strategic Entrepreneurship Journal, 8, 321-348. 
Turban, D. B., \& Cable, D. M. (2003). Firm reputation and applicant pool characteristics. Journal of Organizational Behavior, 24(6), 733-751.

Tykvova, T., \& Walz, U. (2007). How important is participation of different venture capitalists in German IPOs? Global Finance Journal, 17(3), 350-378.

Wadhwa, A., Phelps, C., \& Kotha, S. (2016). Corporate venture capital portfolios and firm innovation. Journal of Business Venturing, 31, 95-112.

Publisher's Note Springer Nature remains neutral with regard to jurisdictional claims in published maps and institutional affiliations. 